\title{
Interconnected Banks and Systemically Important Exposures
}

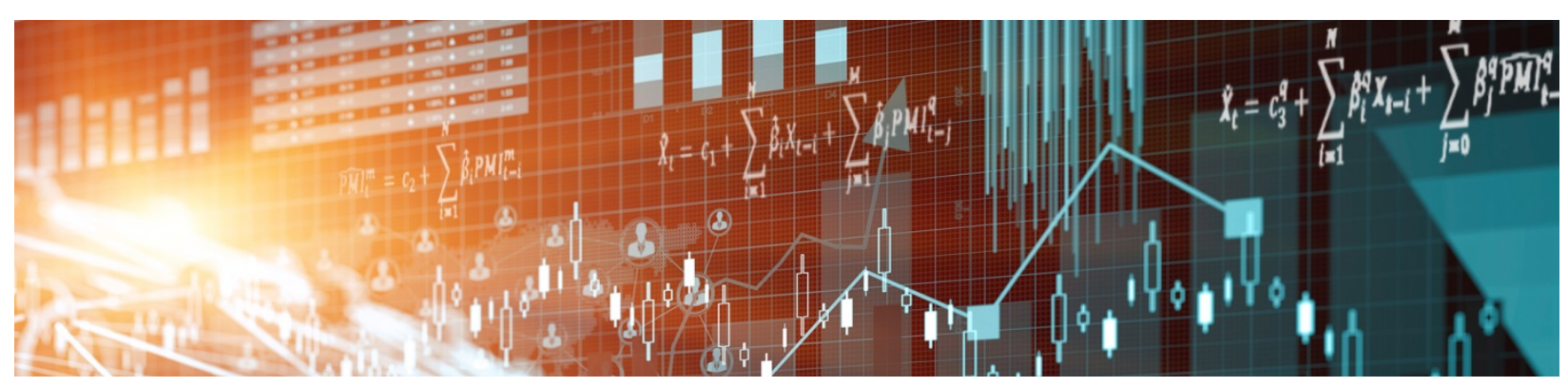

by Alan Roncoroni, Stefano Battiston, Marco D’Errico, Grzegorz Halaj, and Christoffer Kok 
Bank of Canada Staff Working Paper 2019-44

November 2019

\title{
Interconnected Banks and Systemically Important Exposures
}

by

Alan Roncoroni ${ }^{1}$, Stefano Battiston ${ }^{2}$, Marco D'Errico ${ }^{3}$, Grzegorz Halaj ${ }^{3}$, and Christoffer Kok ${ }^{4}$

\author{
'Department of Banking and Finance \\ University of Zurich \\ Switzerland \\ 2European Systemic Risk Board \\ Frankfurt \\ ${ }^{3}$ Financial Stability Department \\ Bank of Canada \\ Ottawa, Ontario, Canada K1A 0G9 \\ GHalaj@bank-banque-canada.ca \\ ${ }^{4}$ European Central Bank \\ Frankfurt
}




\section{Acknowledgements}

Stefano Battiston acknowledges support from the FET Project DOLFINS no. 640772. Alan Roncoroni, Stefano Battiston and Marco D'Errico acknowledge financial support from the Swiss National Science Foundation Professorship, grant no. PP00P1-144689. Alan Roncoroni and Stefano Battiston acknowledge the support from the program on Macroeconomic Efficiency and Stability of the Institute for New Economic Thinking (INET). The authors would also like to acknowledge the participants in the FINEXUS 2018 Conference on financial networks and sustainability at the University of Zurich, the Joint Banco de Portugal/ESRB Workshop 2018, the Bank of Canada internal seminar, the European Commission JRC 1st Conference in Brussels, the Canadian Economic Association Conference 2019, and the FSB/IMF Workshop on Financial Interconnectedness and Systemic Stress Simulation in Washington for their comments. In particular, the authors are grateful to anonymous referees, Paolo Barucca, Seisaku Kameda, Ricardo Sousa, Joseph Stiglitz, Virginie Traclet, Maarten van Oordt and Jan Werner for fruitful discussions and feedback on early versions of this work. The views expressed are those of the authors and do not necessarily represent those of the European Central Bank, the ESRB, the Eurosystem, or the Bank of Canada. 


\begin{abstract}
We study the interplay between two channels of interconnectedness in the banking system. The first one is a direct interconnectedness, via a network of interbank loans, banks' loans to other corporate and retail clients, and securities holdings. The second channel is an indirect interconnectedness, via exposures to common asset classes. To this end, we analyze a unique supervisory data set collected by the European Central Bank that covers 26 large banks in the euro area. To assess the impact of contagion, we apply a structural valuation model NEVA (Barucca et al., 2016a), in which common shocks to banks' external assets are reflected in a consistent way in the market value of banks' mutual liabilities through the network of obligations. We identify a strongly non-linear relationship between diversification of exposures, shock size, and losses due to interbank contagion. Moreover, the most systemically important sectors tend to be the households and the financial sectors of larger countries because of their size and position in the financial network. Finally, we provide policy insights into the potential impact of more diversified versus more domestic portfolio allocation strategies on the propagation of contagion, which are relevant to the policy discussion on the European Capital Market Union.
\end{abstract}

Bank topic: Financial stability

JEL codes: C63, G15, G21 


\section{Introduction}

The financial system is characterized by a wide range of interconnections that can, in various ways, give rise to contagion effects with potentially pernicious implications for financial stability. While direct contagion through, for instance, bilateral links between banks and other financial institutions have long been recognized as an obvious transmission channel, more indirect contagion effects through, for instance, banks' common exposures to similar economic sectors are gaining increasing attention as a potentially more potent channel of contagion (Clerc et al., 2016). This paper studies systemic risk arising both from direct interbank contagion effects and from indirect contagion through portfolio overlaps across economic sectors.

Risks related to asset portfolio overlaps, or, in other words, asset commonality or similarity in business models, have been studied from a theoretical perspective and were assessed as a relevant source of potential contagion losses in the financial system. Risks related to portfolio overlaps are part of the so-called indirect channel of contagion. ${ }^{1}$ So far, the empirical analysis has been conducted either for some isolated sectors of the economy, e.g. Duarte and Eisenbach (2013), Hałaj et al. (2015), Cont and Schaanning (2018) or using broader aggregates of exposures, e.g. Hałaj (2018). However, a systematic analysis of the importance of economic sectors in combination with the country of residence of the obligor is missing.

In order to fill this gap, we propose a new methodology to measure the systemic importance of country sectors throughout the banking systems in monetary terms. We account for both the first-round and second-round losses through the interbank exposures according to a generalized model of contagion. Moreover, we explain the mechanics of different contagion patterns based on the underlying matrix of exposures of banks' portfolios across countries and sectors. Within this framework, different patterns of contagion and different patterns of overlaps can be discerned. We apply our methodology to a unique supervisory data set covering 26 of the largest banks in the euro area along with their exposures to detailed sectors of the real economy (broken down at the level of one-digit $\mathrm{NACE}^{2}$ code) and to other financial institutions.

Other studies have proposed alternative composite systemic risk measures based on network data (see e.g. the Systemic Risk Index by Cont et al. (2013), the Systemic Probability Index by Hałaj and Kok (2013) or the Indirect Contagion Index by Cont and Schaanning (2018)). These other measures try to capture individual banks' risk exposure due to interconnectedness in relation to the banks' buffers against this risk, measured by their capital or counter-balancing capacity of liquid assets.

In the same spirit, we propose a measure that straightforwardly combines overlapping exposures

\footnotetext{
${ }^{1}$ See e.g. Cifuentes et al. $(2005)$, Caccioli et al. (2014), Cont and Wagalath (2014), Cont and Schaanning (2018).

${ }^{2}$ NACE is derived from the French Nomenclature statistique des activités économiques dans la Communauté européenne.
} 
among banks with their capital buffers to assess the indirect channel of contagion transmission. Specifically, we rely on the concept of sectoral leverage overlap ratios that combine three elements: (i) they gauge the shock amplification potential of highly leveraged exposures, (ii) they account for direct contagion channels related to defaulting exposures, and (iii) they include indirect channels capturing asset revaluation and potentially fire sales. We verify the performance of the leverage overlap against the default cascade model of Barucca et al. (2016a), which provides an approach to valuate exposures in financial networks.

Our analysis consists of two complementary blocks that constitute a contribution to the literature on financial interconnectedness. First, we construct a measure of leverage overlaps that, for a given bank and its peer exposed to the same asset class, is a ratio of overlapping volume with the peerbank and the bank's capital. The price-mediated contagion risk related to the commonality of asset holdings is well captured by the proposed measure of overlap between banks. Second, we apply the Network Valuation (NEVA) model of Barucca et al. (2016a) to estimate losses caused by various distress scenarios directly affecting banks' exposures and propagated in the interbank system.

In order to benchmark the transmission of contagion based on the empirical data, we introduce two fictitious allocations of exposures across countries and sectors. In particular, we consider a quasi-domestic allocation in which banks tend to lend to firms and households in their own country and a diversified allocation in which banks maximally diversify their exposures. These two allocations satisfy constraints given by observed sizes of interbank lending and borrowing portfolios and the observed, country-specific sizes of sectors. In addition to these two fictitious allocations of exposures, we observe an empirical one derived from the supervisory data. We analyze the contagion across different dimensions: shock location, shock size, interbank recovery rate, market volatility, and time. The importance of the comparison between these allocations is to provide policy insights into the potential impact of different market structures for contagion risk. The relevance of market structures is for instance highlighted by the well-known result of Wagner (2011) and Acemoglu et al. (2015), which we are able to replicate in our detailed empirical study: a more modular financial system is more fragile than a more diversified financial system to small shocks, while it is more robust to big shocks. Similar results on the impact of diversification on financial stability are discussed in Bardoscia et al. (2017), Silva et al. (2018) and Stiglitz (2018).

Additionally, we benchmark the severity of the stylized shock scenarios by conducting a contagion analysis instigated by loan losses generated under a consistent macro-financial scenario designed for the EU-wide 2016 European Banking Authority (EBA) stress-test exercise. ${ }^{3}$ The results of the analysis are complementary to the first-round accounting losses calculated in the official EU-wide stress test. From a methodological perspective, our approach can be used to enhance the macroprudential assessment

\footnotetext{
${ }^{3}$ http://www.eba.europa.eu/risk-analysis-and-data/eu-wide-stress-testing/2016
} 
of bank stress tests conducted by the European Central Bank (see ECB (2016)).

Our main findings are the following:

1. We find a substantial portfolio overlap on banks' exposures to the financial sector (i.e. other banks and other financial intermediaries). In other words, banks in the sample are similarly exposed to assets that originated from other financial institutions.

2. Measuring the impact of an exogenous shock by the number of defaults allows us to empirically support the theoretical results of Gai et al. (2011), Wagner (2011) and Acemoglu et al. (2015) that more diversified interlinkages mitigate contagion risk for small perturbations in the system but may lead to higher contagion for larger shocks. Specifically, in our setting we find that an internationally diversified network of exposures is more resilient than a more domestic one for small shocks, but less resilient for big shocks.

3. The role of the financial network architecture for risk mitigation or amplification is ambiguous. Some configurations of financial contracts seem to increase financial stability. However, this happens at a cost for external creditors of the banks who would cover losses not absorbed by the banking system.

4. Under the stress scenario of the EBA designed for the 2016 EU-wide stress-test exercise, firstand second-round contagion losses are comparable in size, although there is some heterogeneity across banks. In other words, the financial contagion channel - which tends to be ignored in supervisory stress tests - may have a non-negligible impact on banks' solvency.

5. The measure of the leverage overlap is highly correlated with the outcomes of the fully fledged contagion analysis based on the NEVA methodology. Therefore, we derive a lower bound for losses based on leverage overlap, which is an accurate indicator of systemic risk stemming from overlapping portfolios of banks.

The rest of the paper is structured as follows: in section 2 we discuss the data set, in section 3 we explain the methodology, in section 4 we discuss the results, and in section 5 we conclude the paper.

\section{The data set}

To carry out the analysis we leverage on two confidential data sets collected by the ECB: (1) a supervisory data set of large exposures reporting on banks directly supervised by the ECB, and (2) a ECB proprietary data set on banks' securities holdings (at the security-by-security level). On the basis of these two data sets we have exact and highly granular information about the exposures 
of the 26 largest, systemically important banks in the euro area. The granularity of the data set allows us to identify the country and sector of each exposure. Exposures to external asset classes are divided across six different instruments: loans (89\% of banks' exposures), long-term debt securities (7\%), money market fund (MMF) shares/units (2\%), non-MMF investment fund shares/units $(0.5 \%)$, short-term debt securities $(0.5 \%)$, and listed shares $(2 \%)$. For the sake of simplicity, we treat all the banks' exposures as loans, since they represent the vast majority. ${ }^{4}$ Banks' exposures further span across seven consecutive time snapshots covering 2014-Q4 to 2016-Q2. ${ }^{5}$ For bilateral exposures among banks, we consider information on the following instruments: debt securities and loans (73\% of banks' exposures), equity (5\%), derivatives (13\%), and off-balance-sheet contracts ( $8 \%)$.

There are two key metrics of the banking system derived from the data. First, we collect banks' capital positions in a matrix $E_{i, t}$ which measures banks' capital base in time, i.e. $i$ is the bank index and $t$ the time index.

Second, we build generalized matrices of exposures, $A_{i, c, s, t}$ and leverage generalized matrix, $\Lambda_{i, c, s, t}$, in line with Battiston et al. (2016). Those matrices are multidimensional and are defined as follows.

$A_{i, c, s, t}$ is the amount of money that a bank $i$ invests in country $c$, sector $s$ as of point in time $t$. The definition of a leverage matrix $\Lambda$ directly follows:

$$
\Lambda_{i, c, s, t}=\frac{A_{i, c, s, t}}{E_{i, t}}
$$

$\Lambda_{i, c, s, t}$ can be used in order to assess the first-round (i.e. without considering financial amplifications) relative equity loss of bank $i$ in case of a shock on sector $s$ of country $c$ at time $t$ (Battiston et al., 2016). More information about the granularity of the data (e.g. sector breakdowns) can be found in annex A. The available data dimensions determine the applied methodology described in section 3 .

Tab. 1 shows an overview of banks' total assets and liabilities, total interbank assets and liabilities, and bank equity, as well as some network-related metrics. To measure heterogeneity across banks, we show the average, median, and standard deviation values of the parameters. Interbank assets and liabilities include only bilateral exposures to other banks in the data set.

To illustrate the complexity of the data set used in the analysis, we created a couple of network charts (see Fig. 1). The interbank network presents a relatively dense structure of connections whereas the network of banks' exposures to different economic sectors is more sparse, with banks from the same country clustered according to exposures to the sectors from the same country. The observed clustering reflects a cross-border fragmentation of exposures. ${ }^{6}$ Notably, even though we operate with

\footnotetext{
${ }^{4}$ Note that this assumption does not have any impact on the results of this paper since we focus only on shocks that reduce the value of banks' exposures.

${ }^{5}$ In the current version of the paper, we do not explore the time dimension of the data but focus on the static analysis based on 2016-Q2.

${ }^{6}$ This corroborates statements by the Chairperson of the EBA in his speech, Fragmentation in banking markets:
} 
the 26 largest banks in Europe, constituting the core of the European financial system, some of the banks in the sample prove to be more central than the others (seven banks at a core of the core). The resulting topological complexity of the interbank exposures and of the asset commonality is difficult to understand from a contagion perspective without an in-depth analysis, such as the one proposed in this paper.

\begin{tabular}{r|ccc} 
& Mean & Median & Std \\
\hline Total Assets (€bn) & 399.2 & 330.1 & 314.3 \\
Total Liabilities (€bn) & 361.1 & 300.9 & 288.0 \\
Interbank Assets (€bn) & 9.5 & 7.6 & 8.7 \\
Interbank Liabilities (€bn) & 9.5 & 7.5 & 8.4 \\
\hline \hline Equity (€bn) & 38.1 & 29.2 & 27.6 \\
\hline \hline Total Assets degree & 818.2 & 832 & 496.0 \\
Interbank Assets degree & 8.3 & 9 & 4.7 \\
Interbank Liabilities degree & 8.3 & 7 & 5.9
\end{tabular}

Table 1: Overview of banks' exposures, obligations, and net worth, expressed in billions of euro (as of 2016-Q2). The average, median, and standard deviation value of each parameter are shown. Each number is expressed in billions of euro.

Total Assets degree = number of (country, sector) pairs that a bank is exposed to; Interbank Assets degree $=$ the number of banks a given bank is exposed to; Interbank Liabilities degree $=$ number of banks providing interbank funding to a bank.

crisis legacy and the challenge of Brexit, during the BCBS-FSI High-level Meeting for Europe on Banking Supervision, 17 September 2018. 

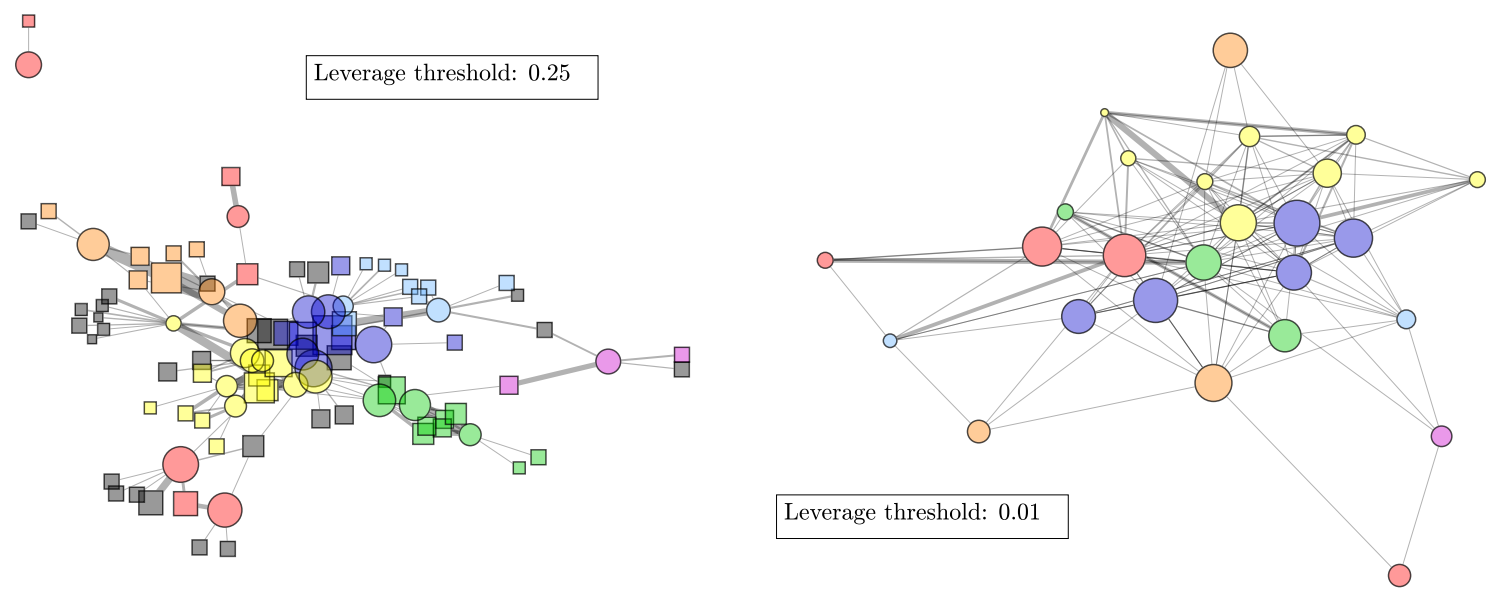

Figure 1: Network structure of banks' exposures to economic sectors (left panel) and on the interbank (right panel). Left: circles denote banks, squares denote sectors; lines between circles and squares indicate exposures of banks (line width proportional to the size of the exposure); colors indicate different sectors of the economy. Right: circles indicate banks; lines indicate interbank exposures (width proportional to the size of the exposure). Force-directed layout algorithm used. Colors indicate countries of domicile. Only significant exposures were presented (left: exposures higher than $25 \%$ of capital; right: interbank exposures higher than $1 \%$ of capital).

\section{Methodology}

We first describe the notion of leverage overlap introduced in Abad et al. (2017), which we apply here for exposures aggregated across countries and sectors. Building on that, we show how to aggregate the leverage overlap across countries and sectors. We then describe the main features of the generalized contagion model, NEVA, used to assess the impact of contagion, including the main ideas that explain why NEVA encompasses other well-established models of financial contagion (i.e. Eisenberg and Noe (2001); Bardoscia et al. (2015)). Additionally, we introduce two different types of fictitious allocations of exposures to assess the impact of diversification and concentration of banks' exposures across countries and sectors of the economy. Finally, we show how the leverage overlap can be used as an indicator to estimate systemic risk.

\subsection{The leverage overlap matrix}

We build on the leverage portfolio overlap metric introduced in Abad et al. (2017) to measure portfolio overlaps in line with those strands of the stress-test literature that account for asset commonality and a price-mediated channel of contagion (see Caccioli et al. (2014); Cont and Schaanning (2018)). The 
goal is to capture common losses suffered by two banks in case of a shock hitting a given sector of the economy. The strength of the proposed measure lies in capturing the combination of risks related to asset commonality and capital adequacy. Therefore, it augments the standard metrics of topological properties of networks based on adjacency matrices enriching nodes' characteristics with the loss absorption capacity of banks.

We define the overlap measure with a generalized matrix $O_{i, j, c, s, t}$, which gauges similarity between banks $i$ and $j$, as

$$
O_{i, j, c, s, t}=\min \left\{\Lambda_{i, c, s, t}, \Lambda_{j, c, s, t}\right\} .
$$

$O_{i, j, c, s, t}$ gives the common relative equity loss of banks $i$ and $j$, in case of a shock on country $c$ and sector $s$ at time $t$. We call the generalised matrix an overlap matrix. By construction, the matrix is symmetric with respect to banks' indexes.

$$
O_{i, j, c, s, t}=O_{j, i, c, s, t}
$$

Moreover, $\Lambda$ can be derived exactly by setting $i=j$. In fact,

$$
\Lambda_{i, c, s, t}=O_{i, i, c, s, t} .
$$

Summing up, the new measure is able to capture both leverage and interconnectedness at the same time.

\subsubsection{Aggregating leverage overlap across countries and sectors}

As shown in Battiston et al. (2016), the relative equity loss of the entire system incurred in the first round $\left(H_{c, s, t}^{\text {total }}\right)$ is proportional to the weighted average of the leverage ratios, provided that the shocks are small. The assumption of the small shocks is necessitated by the limited liabilities of the creditors.

$$
\Lambda_{c, s, t}^{\text {total }}=\frac{\sum_{i}\left(E_{i, t} \cdot \Lambda_{i, c, s, t}\right)}{\sum_{i} E_{i, t}}
$$

An aggregate measure of the impact of the structure of exposures to countries and sectors on the distribution of the common losses in the first round can also be computed.

$$
O_{c, s, t}^{\text {total }}=\frac{\sum_{j} \sum_{i \neq j}\left(E_{i, t} \cdot O_{i, j, c, s, t}\right)}{(N-1) \sum_{i} E_{i, t}}
$$


It is not necessary to sum over $j$ using weights since the addends are already weighted in the sum over $i$. Since the generalized matrix is symmetric with respect to $i$ and $j$, the equity of each bank plays a role in the model. By construction, the following relationship between the generalized matrices holds:

$$
\Lambda_{i, c, s, t} \geq O_{i, j, c, s, t} \quad \text { and } \quad \Lambda_{j, c, s, t} \geq O_{i, j, c, s, t}
$$

It can easily be shown that

$$
O_{i, i, c, s, t} \geq O_{i, j, c, s, t}, \quad \forall i, j, c, s, t
$$

which implies

$$
\Lambda_{c, s, t}^{\text {total }} \geq O_{c, s, t}^{\text {total }}
$$

where we have aggregated the measures on all banks' balance sheets. Tab. 3 shows the top 10 entries of the two matrices $\Lambda_{c, s, t}^{t o t a l}$ and $O_{c, s, t}^{t o t a l}$. We can expect that, even though order is not strictly maintained, there is high correlation between the two measures. This is due to the fact that our measure of overlap not only accounts for the exposure amount but it is also able to predict correlation in losses due to exogenous shocks. We demonstrate the similarities of the two measures in subsection 4.1 .

\subsection{The generalized NEVA model for contagion on networks}

Since we observe that banks' exposures to financial institutions display significant overlaps, the price of banks' obligations depends on the network structure of financial contracts. A theoretical model explaining the relationship between valuation of exposures in the interconnected financial system and the topology of the financial network was developed by Barucca et al. (2016a), and we follow their approach. ${ }^{7}$ The model assumes that a set of banks, interconnected via financial contracts, suffers a loss due to an exogenous shock hitting an external asset class. This decreases banks' equity, which in turn increases their probability of default due to market volatility of the surviving external assets. We want to carry out a valuation of interbank assets before the maturity of contracts. In other words, a bank's equity is a function of not only the expected value of external assets at the maturity but also of the expected value of their investments in the interbank market, which depends on the probability of default of its counterparties.

$$
E_{i}(t)=A_{i}^{e}-L_{i}^{e}+\sum_{j=1}^{N} A_{i, j} \mathbb{V}_{i, j}(\mathbf{E}(t))-\sum_{j=1}^{N} L_{i, j} \quad \forall i
$$

\footnotetext{
${ }^{7}$ Another example of a model that takes into account the interbank network effects on banks' valuations, although a more simplified one, is proposed by Hałaj (2013).
} 
where we consider liabilities $L$ to be fixed. $\mathbb{V}$ is called valuation function and it is used to estimate the value of interbank assets as a function of the equity of the borrower. In the NEVA framework Barucca et al. (2016b), we use a feasible valuation function.

Definition 1. Feasible valuation function

Given an integer $q \leq n$, a function $\mathbb{V}: \mathbb{R}^{q} \rightarrow[0,1]$ is called a feasible valuation function if and only if:

1. it is non-decreasing: $\mathbf{E} \leq \mathbf{E}^{\prime} \Rightarrow \mathbb{V}(\mathbf{E}) \leq \mathbb{V}\left(\mathbf{E}^{\prime}\right), \forall \mathbf{E}, \mathbf{E}^{\prime} \in \mathbb{R}^{q}$,

2. it is continuous from above.

Additionally, we assume that external assets not affected by the exogenous shock follow a geometric Brownian motion with standard deviation $\sigma$ from the time of valuation to maturity. Since a stochastic shock on loans issued by banks is, by construction, confined within interval $[-1,0]$, it cannot be modeled using a Gaussian distribution. In order to satisfy this constraint, the stochastic shocks are modeled using a beta distribution. Additionally, we assume that banks aim to contain the left-handside tail of the distribution by having a risk management strategy such that the shocks on their total asset follow a non-convex distribution. However, since we still want to model extreme events, among all the non-convex beta distribution functions, we chose the one that has the heaviest tail, i.e. the uniform distribution. Furthermore, since the probability of extreme events is by construction higher when modeled with a uniform distribution instead of a log-normal one, the results we obtain from financial contagion when market volatility is large can be considered as an upper bound of losses.

The assumptions imply a unique, maximum valuation function and allow us to compute the network-based value of interbank obligations. ${ }^{8}$ To summarize, the NEVA framework is a generalized model for estimating losses due to financial instability, extending some of the existing models to account for market volatility and partial recovery of defaulted assets.

To measure contagion losses in the system, we define first- and second-round losses. This distinction helps us to isolate losses due to initial shock and loss absorption capacity of banks from those that are incurred by counterparties of the initially shocked banks. Specifically,

- First-round losses due to direct exposure to shocks that are absorbed by the banks initially hit.

- Second-Round losses due to indirect exposures to shocks. Notice that second-round losses include both losses that stem from limited liability (i.e. losses too large to be absorbed by the equity of banks that are directly exposed to the initial shock and are thus transferred to

\footnotetext{
${ }^{8}$ As shown in Barucca et al. (2016a), a set of solutions to NEVA problem is a complete lattice, and in this sense, there is the maximum solution to NEVA.
} 
their counterparties), and losses that stem from amplification (i.e. the effect of uncertainty and financial friction).

Notably, the first-round losses are not equal to the size of the shock that initially hits the system. They are capped by banks' individual capital. A loss exceeding a given bank's capital level is accounted for in the second-round losses since these losses are transmitted to other banks. Some more details on the NEVA framework can be found in annex C.

For each step of the contagion dynamics, we label the financial losses suffered by banks and external creditors using the symbol $\Xi$. For instance, $\Xi_{1 s t, i}$ is the first-round equity loss (in Euro bn) suffered by bank $i$ due to a direct exposure.

\subsubsection{Properties of the contagion dynamics}

Some of the results that we observe empirically can be proven analytically. In order to further contribute to the discussion on the European Capital Market Union, we have formalized the relationship between losses in the domestic and diversified allocation of exposures. For brevity of notation, we have neglected the time indices.

Notably, for specific values of recovery rate $R$ and market volatility $\sigma$, the framework we use in this paper coincides with established models of financial contagion.

Proposition 1. NEVA encompasses the Eisenberg and Noe model.

When $R=1$ and $\sigma=0$, there is a one-to-one correspondence between the solutions of equation (10) and the solutions of the map $\Phi$ introduced in Eisenberg and Noe (2001).

See annex $\mathrm{D}$ for the mathematical proof.

Proposition 2. NEVA encompasses the DebtRank model.

When $R=0$ and $\sigma=1$, there is a one-to-one correspondence between the solutions of equation (10) and the solutions of the recursive map (linear DebtRank) introduced in Bardoscia et al. (2015).

See annex $\mathrm{D}$ for the mathematical proof.

As shown in the empirical results, total losses due to financial contagion depend on the shock size $k$, the recovery rate $R$, and the market volatility $\sigma$. Here, we formalize this dependency throughout a set of propositions. In particular, we show that: (1) total losses cannot decrease when the shock $k$ increases, (2) total losses cannot decrease when the recovery rate $R$ decreases, and (3) total losses cannot decrease when market volatility $\sigma$ increases.

Proposition 3. Losses are non-decreasing with the size of the initial shock $k$. 
If the valuation function $\mathbb{V}$ is feasible, under the same financial network structure, recovery rate $R$ and market volatility $\sigma$,

$$
\Xi_{i}\left(k_{1}, R, \sigma\right) \geq \Xi_{i}\left(k_{2}, R, \sigma\right), \text { if } k_{1} \geq k_{2}
$$

See annex D for the mathematical proof.

Proposition 4. Losses are non-increasing with the recovery rate $R$.

If the valuation function $\mathbb{V}$ is feasible, under the same financial network structure, initial shock $k$ and market volatility $\sigma$,

$$
\Xi_{i}\left(k, R_{1}, \sigma\right) \geq \Xi_{i}\left(k, R_{2}, \sigma\right), \text { if } R_{1} \leq R_{2}
$$

See annex $\mathrm{D}$ for the mathematical proof.

Proposition 5. Losses are non-decreasing with the market volatility $\sigma$.

If the valuation function $\mathbb{V}$ is feasible, under the same financial network structure, initial shock $k$ and recovery rate $R$, losses suffered by each bank after financial contagion cannot be smaller if the market volatility $\sigma$ is larger, i.e.

$$
\Xi_{i}\left(k, R, \sigma_{1}\right) \geq \Xi_{i}\left(k, R, \sigma_{2}\right), \text { if } \sigma_{1} \geq \sigma_{2}
$$

See annex $\mathrm{D}$ for the mathematical proof.

There is growing attention on the impact of portfolio overlap on financial stability. Therefore, we provide a proposition to help to clarify the relationship between leverage overlap and losses due to financial contagion. While the leverage overlap is able to capture the magnitude of common exposures, it fails in estimating network effects of direct exposures. For this reason it should not be used as a stand-alone indicator of systemic risk. We provide an elaborate stylized example of a banking system to discuss the relevance of combined application of overlap measure and network measures in annex E. Similarly, the introduction of asymmetry in the network of leverage exposures to external asset classes also plays a crucial role in the failure of the leverage overlap in entirely capturing systemic risk. Consequently, the leverage overlap only partially captures asymmetries in the network of leverages and does not consider interbank bilateral exposures. For this reason, while it is a useful indicator and less data intensive, a more complete model that considers losses due to indirect exposures should ideally be used in order to monitor systemic risk building up in financial networks. This implies that when the leverage overlap is large, then financial losses due to contagion are also large. 
Proposition 6. There is a relationship between leverage overlap and financial contagion losses.

In the context of limited liabilities, when losses are estimated using Barucca et al. (2016a), the following inequality holds:

$$
H_{c, s}^{\text {total }} \geq k \cdot O_{c, s}^{\text {total }}
$$

where $H_{c, s}^{\text {total }}$ is the total relative equity loss suffered by banks and external creditors weighted on banks' equity, $k$ is the relative shock affecting the country sector, and $O_{c, s}^{\text {total }}$ is the total leverage overlap computed according to equation (6).

See annex $\mathrm{D}$ for the mathematical proof.

Further, in two propositions we clarify the impact of the structure of financial networks and financial stability. In the diversified allocation of exposures, banks are exposed to all country sectors. We show that as a result of this exposure, when one or more sectors are shocked, the capital of all banks is used to absorb the initial loss. For this reason, losses are mutualized and the threshold of limited liability is hardly ever reached. Note that, for small shocks, banks are able to absorb the initial loss with their capital in the domestic allocation of exposures as well. The inequality in Proposition (7) thus becomes an equality and the aggregate first-round losses suffered by banks in the two allocations of exposures are equivalent. Similarly, in the diversified allocation of exposures, the incurred losses are mutualized among all banks: it follows that, in respect to the domestic allocation of exposures, a larger share of banks' capital is used to absorb losses. It is straightforward to conclude that losses for external creditors in the diversified allocation of exposures are smaller than losses suffered by external creditors in the domestic allocation of exposures. For this reason, the architecture of the domestic allocation of exposures ring-fences banks, confining most of the losses in the shocked countries and dividing them among banks and external creditors of those countries.

Proposition 7. There is a relationship between first-round losses in domestic and diversified settings.

Under assumption of limited liabilities, when the exogenous shock only hits a single asset class, first-round losses in the domestic setting $\Xi_{1 \text { st }}^{\text {dom }}$ are never larger than first-round losses in the diversified setting $\Xi_{1 \text { st }}^{\text {div }}$, i.e.

$$
\Xi_{1 \mathrm{st}}^{\mathrm{div}} \geq \Xi_{1 \mathrm{st}}^{\mathrm{dom}}
$$

See annex $\mathrm{D}$ for the mathematical proof.

Proposition 8. There is a relationship between losses suffered by external creditors in domestic and diversified settings.

Under assumption of limited liabilities, losses suffered by external creditors in the diversified setting 
$\Xi_{\text {ext }}^{\text {div }}$ are never larger than losses suffered by external creditors in the domestic setting $\Xi_{\text {ext }}^{\text {dom }}$, i.e.

$$
\Xi_{\mathrm{ext}}^{\mathrm{div}} \leq \Xi_{\mathrm{ext}}^{\mathrm{dom}}
$$

See annex $\mathrm{D}$ for more details and the mathematical proof.

\subsection{Alternative allocation of financial exposures across banks}

In order to study the impact of financial network architectures we build two alternative allocations of exposures. We will call the first one the diversified allocation of exposures and the second one the domestic allocation of exposures. We will use those two extreme allocations of exposures as benchmarks to compare and understand the empirical results on contagion.

Definition 2. Diversified allocation of exposures

We defined as diversified allocation of exposures the network structure where banks invest in all assets classes, regardless of the geographical dimension, proportionally to asset classes size.

Definition 3. Domestic allocation of exposures

We defined as domestic allocation of exposures the network structure where banks first invest in assets classes in their own country proportionally to asset classes size. Cross-border investments are then allocated proportionally to the remaining demand in each asset class.

The motivation behind this allocation study is to analyze how financial stability is affected in case of a substantial change in banks' strategies due to, for instance, the introduction of a new prudential regulation. By keeping the size of each country sector fixed and by satisfying banks' balance-sheet constraints, we reshuffle banks' exposure in order to generate two extreme synthetic asset allocations. In the first allocation, called diversified, banks do not care about the location or type of country sectors and spread their assets among them in proportion with their size. In the second allocation, called domestic, banks allocate their exposures in the economy of their own country, in proportion to the size of the sectors.

We acknowledge that the assumption regarding unchanged capital buffers for different allocations of exposures may be a simplified one. Following the rules of capital requirements, a change of allocations of exposures may imply a different concentration of exposures that require additional capital buffers (Düllmann and Masschelein, 2007). However, our simplified treatment of capital levels as insensitive to the concentration of banks' assets is rather conservative, given that the domestic allocation of exposures is similar to the observed distribution of exposures across countries and sectors, and, therefore, the diversified allocations should receive the benefit of lower capital requirements. 
A more detailed description of how the two synthetic allocations were built can be found in annex B

Interbank networks are also generated consistently with the two types of allocations of exposures to the real economy and non-bank financial institutions and respecting the constraints imposed by banks' balance sheets. To maintain consistency between geographical distribution of exposures to sectors excluding banks and the geographical distribution of exposures on the interbank market for each of the two scenarios, we consider two ensembles of the interbank linkages. Both are based on the simulated network approach of Hałaj and Kok (2013). In a nutshell, the simulated network procedure randomly samples interbank structures using a version of an accept-reject algorithm. To this end, linkages are drawn from a uniform distribution and accepted with a predefined probability $p_{i j}$ of an exposure being extended between two given banks, $i$ and $j$. By a specific assignment of probabilities to the links, the algorithm can yield a desired topology of the network. Notably, in both cases the algorithm yields different structures depending on the sequence of pairs of banks that are drawn. The first ensemble of the simulated interbank networks is sampled under the assumption of full diversification across counterparties. This is achieved by taking a probability map with all entries equal to 0.1 (except for the diagonal where probabilities are equal to zero to avoid self loops). In this way, the exposures are spread most evenly across the market and the only constraint is the total initial interbank lending and borrowing of each bank. The second ensemble is drawn in such a manner that the exposures are domestically concentrated. The probability map is a block matrix such that $p_{i j}=0.1$ if and only if banks $i$ and $j$ are from the same country, otherwise $p_{i j}=0$. Since for some of the countries, the net interbank exposures are significantly different from zero, ${ }^{9}$ part of the exposures cannot be allocated domestically; and to attain the size of the system comparable with the observed (and diversified one), we allocate the remaining portion across borders (i.e. $p_{i j}:=0.1$ if and only if $i$ and $j$ are from different countries). Consequently, we achieve a quasi-domestic allocation of exposures. For the scenario analysis of the country-sector overlaps, we pick one simulated diversified and one simulated domestic network that are most diversified and have the highest share of domestic exposures, respectively.

\subsection{Overlap as systemic risk indicator}

As seen in the previous sections, the leverage overlap can be used to measure to what extent the portfolios of two banks are similar. Additionally, the leverage overlap can be used to characterize a lower bound for losses induced by an exogenous shock. We will then show that if

- banks are grouped in communities such that the leverage portfolio (i.e. banks' exposures nor-

\footnotetext{
${ }^{9}$ I.e. banks are net lenders or net borrowers on the interbank market.
} 
malized by their equity) is equal across banks of the same community

- interbank exposures are uniform across banks, i.e. $\bar{\Lambda}^{b}=\Lambda_{i j}^{b}, \forall i \neq j$,

then the lower bounds (21) and (23) expressed as functions of leverage overlap correspond exactly to the losses. ${ }^{10}$

Let us consider a set of $N$ banks that invested into some country sectors and are exposed to each other via bilateral contracts, such as loans. According to the literature, ${ }^{11}$ direct losses due to an exogenous relative shock $k_{c s}$ hitting the country sector $c s$ can be expressed as

$$
h_{i}^{1^{s t}}=\min \left\{1, \sum_{c} \sum_{s} \Lambda_{i c s} \cdot k_{c s}\right\} \text {, }
$$

where $k$ is a matrix whose elements $k_{c s}$ describe the relative shocks decreasing the value of investments in country sector $c s$.

Let us now divide the $N$ banks into communities labeled $I$. As presented in subsection 3.1.1, the term $\min \left\{1, \sum_{c} \sum_{s} O_{i j c s} k_{c s}\right\}$ corresponds to the common relative equity loss suffered by banks $i$ and $j$. Similarly, building on equation (17), we can describe the common relative equity loss suffered by all banks in community $I$ as

$$
\tilde{h}_{I}^{1^{s t}}=\min \left\{1, \sum_{c} \sum_{s} O_{I c s} \cdot k_{c s}\right\},
$$

where $O_{I c s}$ is the community leverage overlap over country-sector pair $(c, s)$ and is defined as

$$
O_{I c s}=\min _{i j \in I}\left\{O_{i j c s}\right\}
$$

Since $\forall i, j \in I \quad \Lambda_{i c s} \geq O_{i j c s} \geq O_{I c s}$, we can compare first-round losses expressed with leverage and with leverage overlap,

$$
h_{i}^{1^{s t}} \geq \tilde{h}_{I}^{1 s t}, \forall i \in I .
$$

\footnotetext{
${ }^{10}$ The overlap matrix gauges the extent to which shocks may be propagated via a fire-sale channel. However, we do not consider a price-mediated channel of contagion due to a material uncertainty about sensitivities of valuation of assets to fire-sale prices. Moreover, many assets classes that we consider (e.g. mortgage or corporate loans) are recognized at amortized costs and are not subject to marked-to-market revaluation, and therefore outstanding volumes of assets are insensitive to transaction prices in fire sales.

${ }^{11}$ See Eisenberg and Noe (2001); Rogers and Veraart (2013); Battiston et al. (2012); Bardoscia et al. (2015); Barucca et al. (2016a)
} 
Total relative equity loss after the first round thus reads as

$$
\begin{aligned}
H^{1^{s t}}= & \frac{\sum_{i} h_{i}^{1^{s t}} E_{i}}{\sum_{i} E_{i}}=\frac{\sum_{I} \sum_{i \in I} h_{i}^{1^{s t}} E_{i}}{\sum_{i} E_{i}} \geq \\
\geq & \frac{\sum_{I} \sum_{i \in I} \tilde{h}_{I}^{s s} E_{i}}{\sum_{i} E_{i}}=\frac{\sum_{I} \tilde{h}_{I}^{1^{s t}} E_{I}}{\sum_{I} E_{I}},
\end{aligned}
$$

where $E_{I}=\sum_{i \in I} E_{i}$ is the total initial equity of banks in the community $I$.

Similarly, a lower bound for second-round losses due to contagion to first neighbors can be expressed as a function of leverage overlap, and it is expressed as

$$
\begin{aligned}
h_{i}^{1^{s t}+2^{n d}} & =\min \left\{1, h_{i}^{1^{s t}}+(1-R) \sum_{j} \Lambda_{i j}^{b} h_{j}^{1^{s t}}\right\} \geq \\
& \geq \min \left\{1, \tilde{h}_{i}^{1^{s t}}+(1-R) \sum_{j} \Lambda_{i j}^{b} \tilde{h}_{j}^{1^{s t}}\right\}= \\
& =\min \left\{1, \tilde{h}_{i}^{1^{s t}}+(1-R) \sum_{I} \tilde{h}_{j}^{1^{s t}} \sum_{j \in I} \Lambda_{i j}^{b}\right\} \approx \\
& \approx \min \left\{1, \tilde{h}_{i}^{1^{s t}}+(1-R) \bar{\Lambda}^{b} \sum_{I} \tilde{h}_{j}^{1^{s t}} \sum_{j \in I} 1\right\}=\tilde{h}_{I}^{1^{s t}+2^{n d}}
\end{aligned}
$$

with $R$ being a recovery rate. Total relative equity loss due to first- and second-round losses is then defined as

$$
H^{1^{s t}+2^{\text {nd }}}=\frac{\sum_{I} \sum_{i \in I} \tilde{h}_{i}^{1^{s t}+2^{\text {nd }}} E_{I}}{\sum_{I} E_{I}} .
$$

We have developed a lower bound for losses due to financial contagion, which is expressed as a function of leverage overlap. Notably, as shown in Battiston et al. (2016), second-round losses can be expressed by means of a first-order contagion. Moreover, when the interbank network is uniform, the approximation of losses using mean leverage gives the exact measure of the losses. Additionally, for both first- and second-round effects, when the community overlap corresponds to the leverage of each bank that belongs to the community, the lower bound is equal to the losses computed using the leverage matrix. Since both the lower bounds for first- and second-round losses expressed as a function of overlap are increasing with the overlap itself, we conclude that community overlap can be 
considered as a systemic risk indicator and should be monitored together with indicators of leverage. Large overlap means that banks have large common exposure that could open a price-mediated channel of distress propagation and amplify systemic risk related to the direct interlinkages.

\section{Results}

We present the results of the analysis in five steps: (i) statistical properties of the networks of exposures, (ii) evaluation of the leverage overlap as an indicator for financial stability, (iii) measurement of contagion effects following the NEVA methodology of Barucca et al. (2016a), (iv) theoretical results on financial contagion, and ( $\mathrm{v}$ ) assessment of contagion under the adverse scenario of the EBA 2016 stress-test exercise, following Barucca et al. (2016a).

\subsection{Descriptive statistics of alternative banking structures}

In this section, we compare the very basic properties of the three different allocations of exposures. Tab. 2 shows both the ratio of domestic and cross-border exposures with respect to banks' total assets and the network density of the three allocations of exposures. It can be observed that banks' exposures to non-financial sectors in the empirical allocation of exposures are mostly domestic. Notably, the diversified cross-border exposures are also present by construction in the domestic allocations since they are a necessary outcome of the matching algorithm described in section 3.3 to satisfy total lending and borrowing constraints. At the same time, interbank linkages in the empirical allocation of exposures are spread internationally.

\begin{tabular}{c|ccc|ccc}
\multicolumn{3}{c}{ Non-financial exposures } & \multicolumn{3}{c}{ Interbank } \\
\hline & Domestic & Global & Density & Domestic & Global & Density \\
\hline \hline Empirical & $59.93 \%$ & $40.07 \%$ & 0.12 & $33.46 \%$ & $66.54 \%$ & 0.33 \\
\hline Diversified & $15.57 \%$ & $84.43 \%$ & 0.50 & $15.70 \%$ & $84.30 \%$ & 1.00 \\
\hline Domestic & $75.09 \%$ & $24.91 \%$ & 0.43 & $70.33 \%$ & $29.67 \%$ & 0.33
\end{tabular}

Table 2: Comparison of different allocations of exposures. The percentages show the ratio of assets invested in domestic or cross-border asset classes, respectively, for each type of exposure (interbank or non-bank counterparts, respectively) and each allocation. The density, on the other hand, shows the number of contracts divided by the total possible number of pairs of banks and asset classes and bank-to-bank linkages that can be established. Data for 2016-Q2 are shown.

Fig. 2 shows some descriptive statistics regarding banks' exposures. On the left-hand side, one can observe that the largest exposure of banks is to the household sector and is mainly domestic. The second largest exposure of banks is to the financial system (to both credit institutions and other 
financial institutions) and is mainly cross-border. Obviously, exposures to the non-financial corporate sector are also sizable but are spread across different sub-sectors. The most sizable non-financial corporate exposures are real estate activities, manufacturing and wholesale, and retail trade. While in the case of the former category, exposures are predominantly domestic, the latter two also contain a large share of cross-border exposures. Additionally, the right-hand side of Fig. 2 shows that banks have large portfolio overlaps on the financial system and that the overlap is large both between banks from the same country and between banks from different countries. Observing this large overlap is equivalent to observing that banks' portfolios are very similar to each other, which in turn means that an idiosyncratic shock would likely have a very correlated impact on banks' balance sheets. Moreover, since banks' portfolio overlap is very high concerning exposures to the financial system, we deduce that banks are interconnected via a very dense network of contracts. ${ }^{12}$ For these reasons, we conclude that a network approach is necessary to adequately compute the fair value of an interbank obligation and that this value might actually be substantially lower than its book value. Moreover, we observe tension between the domestic dimension of real economy assets commonality and the global dimension of intra-financial exposures.
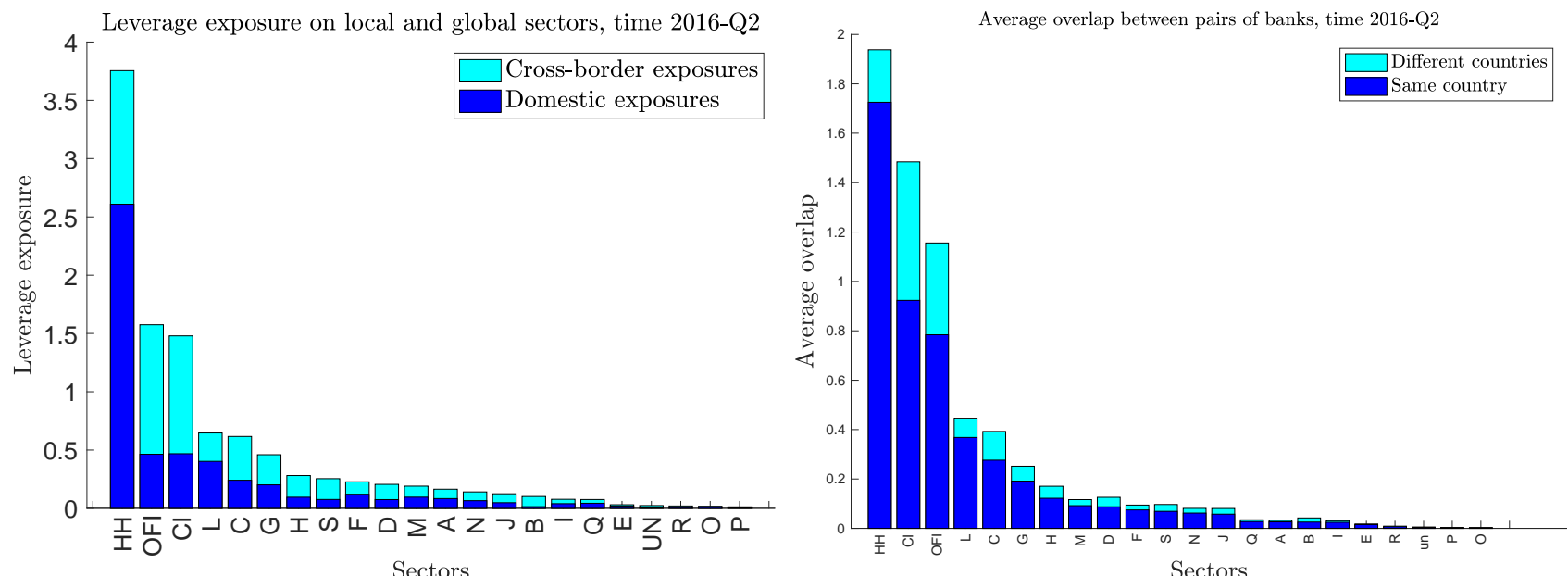

Figure 2: Statistics on banks' allocation of exposures in the empirical setting. Left: exposures per unit of capital. The blue bar shows the ratio of exposures allocated to domestic sectors, while the cyan bar shows the ratio of exposures allocated to cross-border sectors. Right: average portfolio overlap on each sector. The blue bar shows the average overlap between pairs of banks from the same country, while the cyan bar shows the average portfolio overlap between pairs of banks from different countries.

\footnotetext{
${ }^{12}$ High density of the network can be expected since we operate with the 26 largest banks at the core of the EU financial system.
} 
By breaking down sectoral exposures into countries, we can look deeper into the potential channels of contagion stemming from portfolio overlaps. A ranking of country sectors is presented in Tab. 3. The household sector dominates the total leverage column, while more credit institutions appear in the column showing overlapped leverage. This indicates the usefulness of the overlap measure in revealing potential vulnerabilities related to commonality of interbank - or, more broadly, intra-financial exposures.

It is also important to note that the FR-HH country sector is much larger than the others because of the fact that we consider only the 26 European systemically important banks, and the French financial sector is known to be very concentrated. ${ }^{13}$ In other words, given the nature of our sample the market coverage of the French banking sector is by consequence significantly larger than in some of the other euro area countries with a lower banking sector concentration.

\begin{tabular}{c|ll|ll} 
Ranking & \multicolumn{2}{|c|}{$\Lambda_{c, s, t}^{\text {total }}$} & \multicolumn{2}{c}{$O_{c, s, t}^{\text {total }}$} \\
\hline \hline 1 & FR-HH & 1.25700 & FR-CI & 0.16545 \\
2 & NL-HH & 0.56692 & FR-HH & 0.14291 \\
3 & DE-HH & 0.50620 & DE-HH & 0.13420 \\
4 & FR-CI & 0.38305 & GB-CI & 0.11617 \\
5 & IT-HH & 0.37354 & US-OFI & 0.11546 \\
6 & DE-CI & 0.35618 & DE-CI & 0.10090 \\
7 & US-OFI & 0.32301 & US-CI & 0.07351 \\
8 & GB-HH & 0.23632 & GB-OFI & 0.06643 \\
9 & ES-HH & 0.22538 & ES-CI & 0.05238 \\
10 & FR-OFI & 0.18123 & IT-HH & 0.03818
\end{tabular}

Table 3: Top 10 country sectors ranked both by total leverage and by overlap of the 26 major European banks, for the fourth quarter of 2014. $\Lambda_{c, s, t}^{\text {total }}$ and $O_{c, s, t}^{\text {total }}$ are computed according to equations (5) and (6) respectively.

\subsection{Assessing contagion under stylized shock scenarios}

In order to assess the impact of an exogenous shock on the financial system conditional upon an initial exogenous shock and a given market volatility we apply Barucca et al. (2016a). Fig. 3 shows the impact on the financial system, as a function of the relative exogenous shock. A plot on the left-hand side measures the impact as number of defaults; the plot on the right-hand side considers the relative equity loss. For illustration, we have selected three countries (Germany, France, and the Netherlands) and assumed a stress scenario affecting exposures to the corporate sectors of these countries.

\footnotetext{
${ }^{13}$ Chart 2.10 in the Report on Financial Structures (October 2017), European Central Bank. https://www.ecb. europa.eu/pub/pdf/other/reportonfinancialstructures201710.en.pdf
} 
When considering the number of defaults, we can distinguish three stress regimes: (1) for very small shocks, no default is observed in the system; (2) for intermediate but still rather small shocks, the diversified allocation of exposures is more robust than the domestic one; and (3) for very large shocks, the diversified allocation of exposures is more fragile than the domestic allocation of exposures. This result is in line with Acemoglu et al. (2015) and is explained by the fact that a domestic network has a more modular and fragmented structure that prevents the shocks from being easily spread across the system. In fact, in the domestic allocation where mainly domestic banks are responsible for the size of exposures for a given country and sector, the largest loss that can be propagated to other countries is equivalent to the liabilities of the banks in the shocked country. For this reason, the number of defaults does not increase after the shock reaches a threshold estimated at around $70 \%$. On the other hand, in the diversified allocation of exposures, first-round losses are diluted among all banks; similarly second-round losses can affect all banks at the same time. This is why the number of defaults does not saturate and increases with the severity of the initial shock. Visentin et al. (2016) show that in the absence of frictions - i.e. when the recovery rate is equal to one - the network effects are zeros. Losses cannot be amplified but only spread among market participants. When relaxing the assumptions on contagion, thus considering a non-zero market volatility and a recovery rate on interbank assets lower than one, the number of defaults is not an appropriate measure of the stability of the financial system since it does not quantify the magnitude of losses. The relative equity loss $H_{k}$, defined as

$$
\begin{aligned}
H_{k} & =\frac{\sum_{i=1}^{N} E_{i}(0)-E_{i}(T)}{\sum_{i=1}^{N} E_{i}(0)}= \\
& =\frac{\sum_{i=1}^{N} \Xi_{i}}{\sum_{i=1}^{N} E_{i}(0)}= \\
& =\frac{\Xi}{\sum_{i=1}^{N} E_{i}(0)}
\end{aligned}
$$

should be used instead. $E_{i}(0)$ represents the equity of bank $i$ before the exogenous shock, while $E_{i}(T)$ represents the equity of bank $i$ after distress propagation. Notice that we have defined as $\Xi_{i}$ the equity loss suffered by bank $i$ and as $\Xi$ the total equity loss suffered by banks. By expressing the impact using the total relative equity loss suffered by the system, we can see in Fig. 3, right panel, that a smaller number of defaults does not mean that the system is more stable. In fact, for small and intermediate shocks, the three allocations of exposures are more or less equivalent. However, for large shocks, the diversified allocation is less stable than the domestic allocation for the same reasons explained above.

Furthermore, the right-hand side of Fig. 3 highlights the role of the structure of the financial network for distributional effects. The solid blue, red, and green lines represent total losses suffered 
by banks and external creditors. However, dashed lines of the same colors represent the portion of losses that are absorbed by banks. Thus, it follows that the differences between solid and dashed lines of the same colors represent the portion of losses suffered by the external creditors. Additionally, the solid black line represents the initial loss due to the shock on the asset classes. While total losses suffered by banks and external creditors are comparable in the three different allocation of exposures, the amount absorbed by only by the banking sector differs substantially. In fact, the structure of the diversified allocation of exposures distributes losses among a larger number of banks, insulating external creditors that bear a smaller amount of losses compared with the domestic allocation of exposures. The difference between the solid black line and the solid colored lines represents the losses due to amplification caused by financial friction and uncertainty. In summary, the figure shows the friction between financial stability, represented by amplification of losses, and the social aspect of loss distribution.
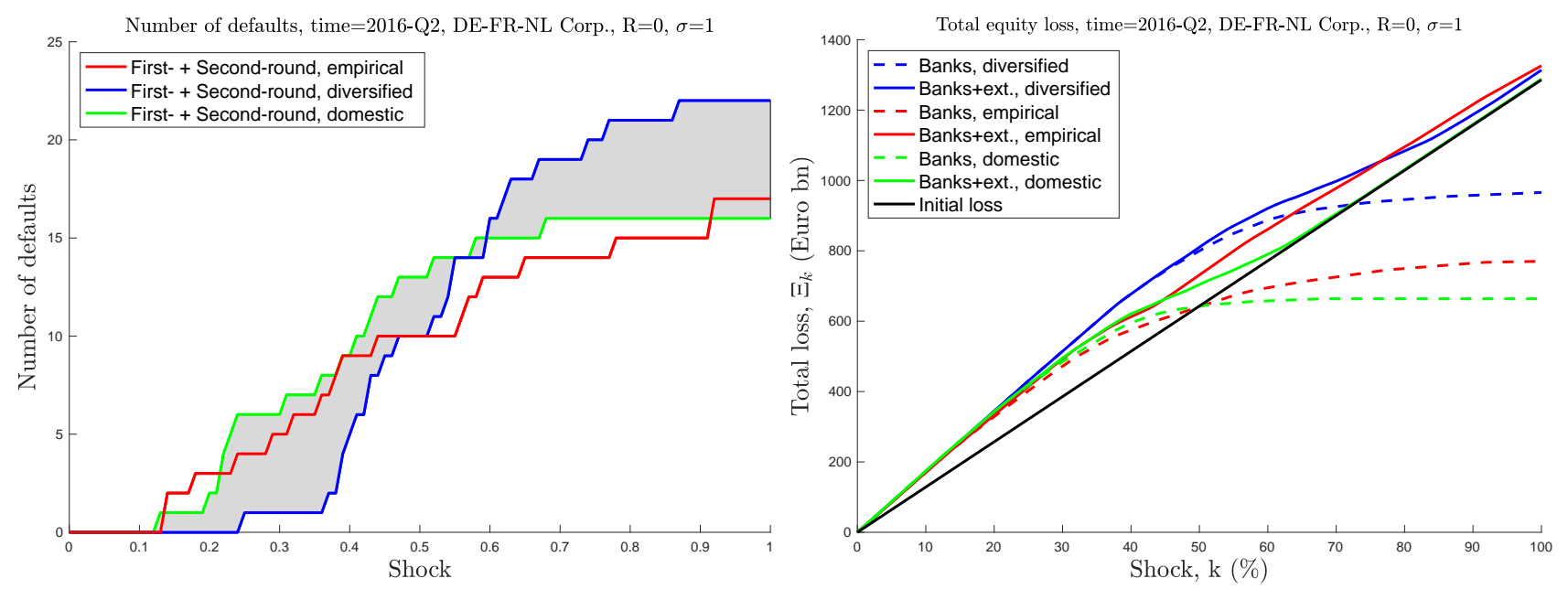

Figure 3: Impact of an exogenous shock on the corporate sectors of a selected number of countries as a function of the shock size. Left: number of defaults as a function of the exogenous shock on the corporate sectors under the assumption that banks are able to recover $0 \%$ of their interbank assets from defaulting counterparties and market volatility 1 . The gray surface highlights the crossover between the two fictitious allocations of exposures. Right: loss suffered by banks and external creditors, under the assumption that banks are able to recover $0 \%$ of their interbank assets from defaulting counterparties and market volatility 1 . The dashed lines represent losses suffered by banks. Solid blue, red, and green lines represent total losses suffered by banks and external creditors. The difference between solid and dashed lines of the same color represents losses suffered by external creditors. The lines are color coded as follows: red - empirical; green - domestic; blue - diversified allocations of exposures; and black - initial loss.

In Figs. 4 and 5 we show the impact of an exogenous shock (50\% and $10 \%$ of the affected asset 
class, respectively) under different assumptions for market volatility and recovery rates. The $50 \%$ loss may seem to be overly severe even for a potentially risky corporate sector. Therefore, as a sensitivity analysis, we run the simulations for a milder yet adverse scenario with a $10 \%$ loss rate. We aggregate exposures subject to a shock scenario to two groups: (i) for some core countries and (ii) for peripheral countries more severely affected by the recent great financial crisis and ensuing sovereign debt crisis (i.e. Spain, Greece, Ireland, Italy, and Portugal). The initial losses are shown by the gray bar. Losses in the diversified, empirical, and domestic allocation of exposures are shown by the blue, red, and green bars, respectively. Notice that the gray bar is shown in order to compare initial losses and total losses that account for uncertainty and financial friction. For this reason, the amount by which blue, red, and green bars exceed the gray bar coincides exactly with the amplification in the three different allocations of exposures. Additionally, the bars showing losses in the diversified, empirical, and domestic allocation of exposures are split into three parts that are highlighted by different levels of opacity: (i) the section on the left shows first-round losses, (ii) the middle section shows second-round losses, and (iii) the section on the right shows the losses that are transferred to external creditors.

In the left-hand side of the chart, we assume that the recovery rate is one and market volatility is zero. This coincides with the assumptions made in Eisenberg and Noe (2001). In the absence of financial frictions, final losses suffered by banks and external creditors coincide with the initial exogenous shock under any network architecture (Visentin et al., 2016). For this reason the size of the blue, red, and green bars is equivalent to the size of the gray bar. However, when the architecture changes, the losses are either accounted for under different steps of the distress propagation (first or second rounds) or suffered by external creditors. When referring to external creditors, we account for losses suffered by other banks not belonging to the 26 European systemically important banks, other financial institutions, or even depositors. While the financial system seems to be less robust to such big shocks, we see that this translates only to fewer losses suffered by external creditors, since the total loss, by construction, remains constant. Interestingly, in the case of shocks to core countries, the second-round effects are much larger in relative terms for the observed (empirical) topology of the market than they would be for either the domestic or the diversified network of exposures. Notably, the shock of $10 \%$ is not large enough to generate distressful contagion effects and all losses are confined to the first round of the loss propagation mechanism.

On the right-hand side of Figs. 4 and 5 we show the impact of the same $50 \%$ and $10 \%$ shocks when relaxing the assumptions on the recovery rate and imposing a higher market volatility. The role of the financial architecture is ambiguous. However, amplification of losses in the diversified allocation of exposures is typically larger than in the empirical or domestic allocation. In fact, the amount by which the blue bar exceeds the gray bar is larger than for the red or green bars. Additionally, losses suffered by external creditors in the diversified allocation are typically lower than in the empirical or 
domestic allocation. This last result is explained by the fact that the architecture of the diversified allocation distributes losses across a large number of banks. Thus, a larger capital base is used to absorb losses before affecting external creditors.
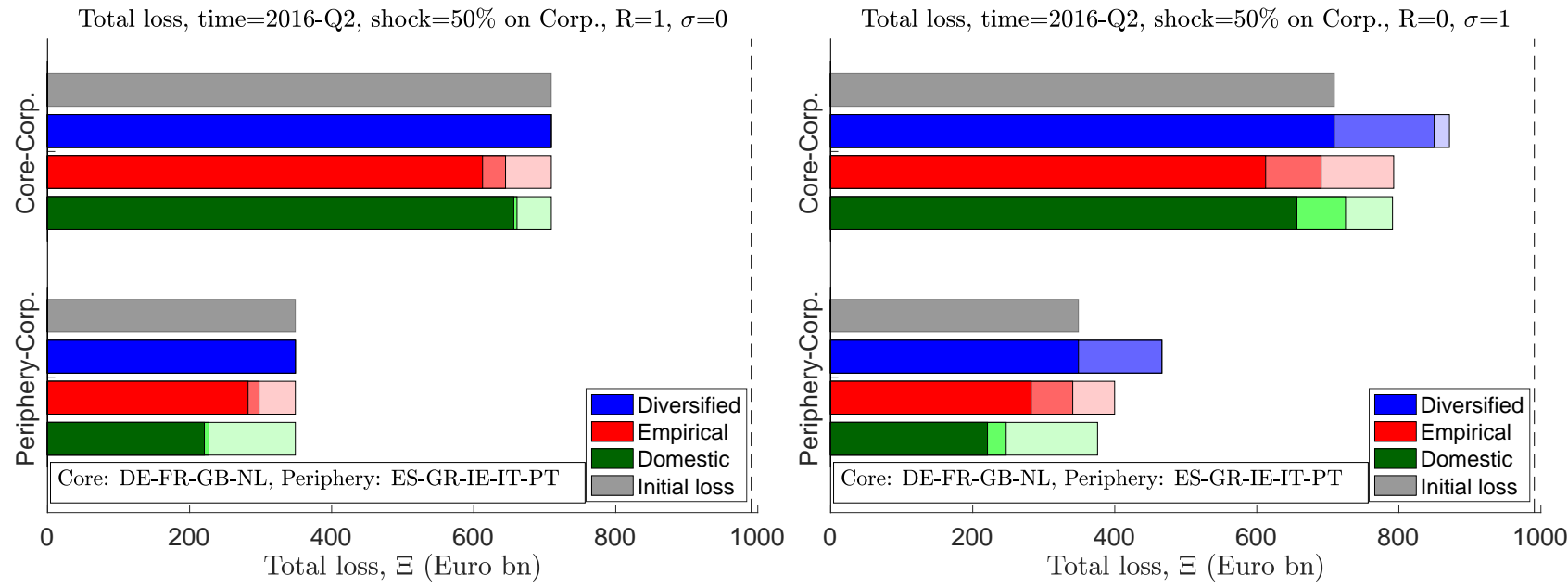

Figure 4: Impact of an exogenous shock on the financial system originating from the aggregate corporate sector of selected countries. Each collection of countries is associated with four bars: (1) the gray bar represents the initial loss in value suffered by the country sector without considering network effects, (2) the blue bar represents losses suffered by the financial system under the diversified allocation of exposures assumption, (3) the red bar represents losses suffered by the financial system in the empirical setting, and (4) the green bar represents losses suffered by the financial system under the domestic allocation of exposures assumption. Additionally, each bar, except for the gray one, is split into three parts: (1) the darkest part represents the first-round losses, (2) the middle part represents the second-round losses, and (3) the lightest part represents losses suffered by creditors that are external to the financial system considered in this project. Additionally, the dashed vertical line represents the total equity in the system. Left: $50 \%$ shock on the selected country sectors under the assumption of a 100\% recovery rate of interbank assets and 0\% market volatility. Right: $50 \%$ shock on the selected country sectors under the assumption of a $0 \%$ recovery rate and $100 \%$ market volatility. 

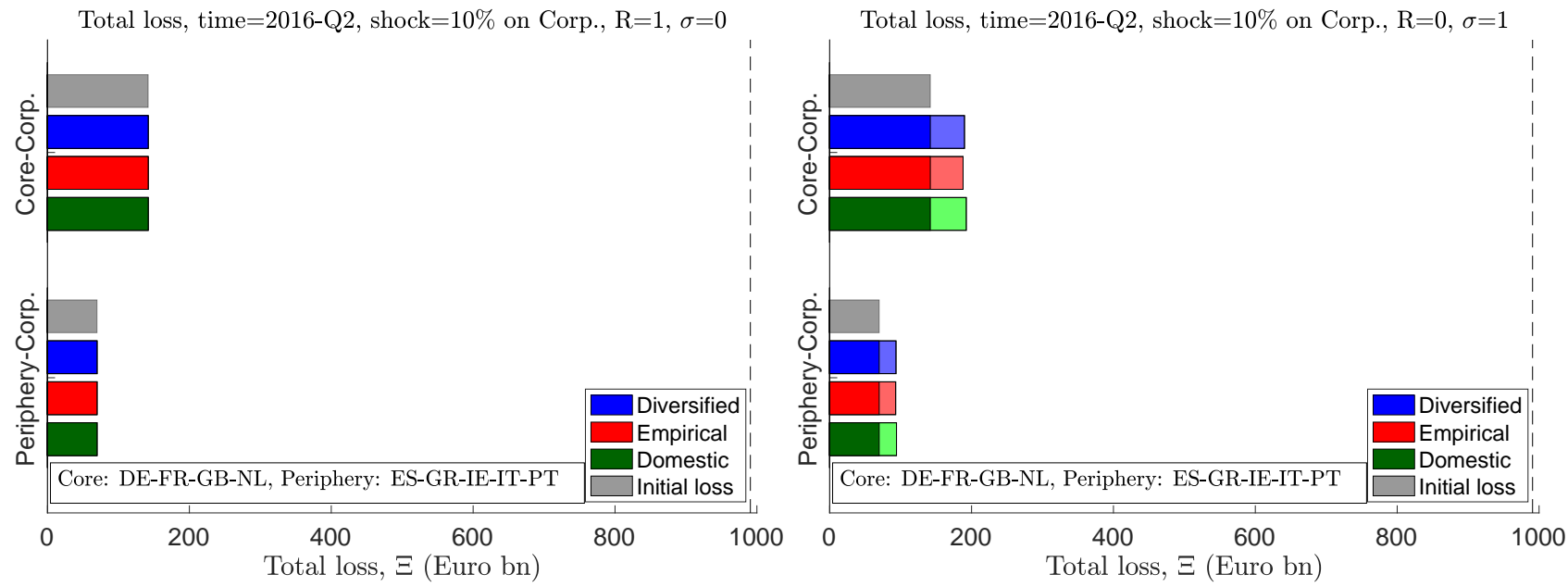

Figure 5: Impact of an exogenous shock on the financial system originating from the aggregate corporate sector of selected countries. Each selection of countries is associated with four bars: (1) the gray bar represents the initial loss in value suffered by the country sector without considering network effects, (2) the blue bar represents losses suffered by the financial system under the diversified allocation of exposures assumption, (3) the red bar represents losses suffered by the financial system in the empirical setting, and (4) the green bar represents losses suffered by the financial system under the domestic allocation of exposures assumption. Additionally, each bar, except for the gray one, is split into three parts: (1) the darkest part represents the first-round losses, (2) the middle part represents the second-round losses, and (3) the lightest part represents losses suffered by creditors that are external to the financial system considered in this project. Additionally, the dashed vertical line represents the total equity in the system. Left: $10 \%$ shock on the selected country sectors under the assumption of a 100\% recovery rate on interbank assets and 0\% market volatility. Right: $10 \%$ shock on the selected country sectors under the assumption of a $0 \%$ recovery rate and $100 \%$ market volatility. 

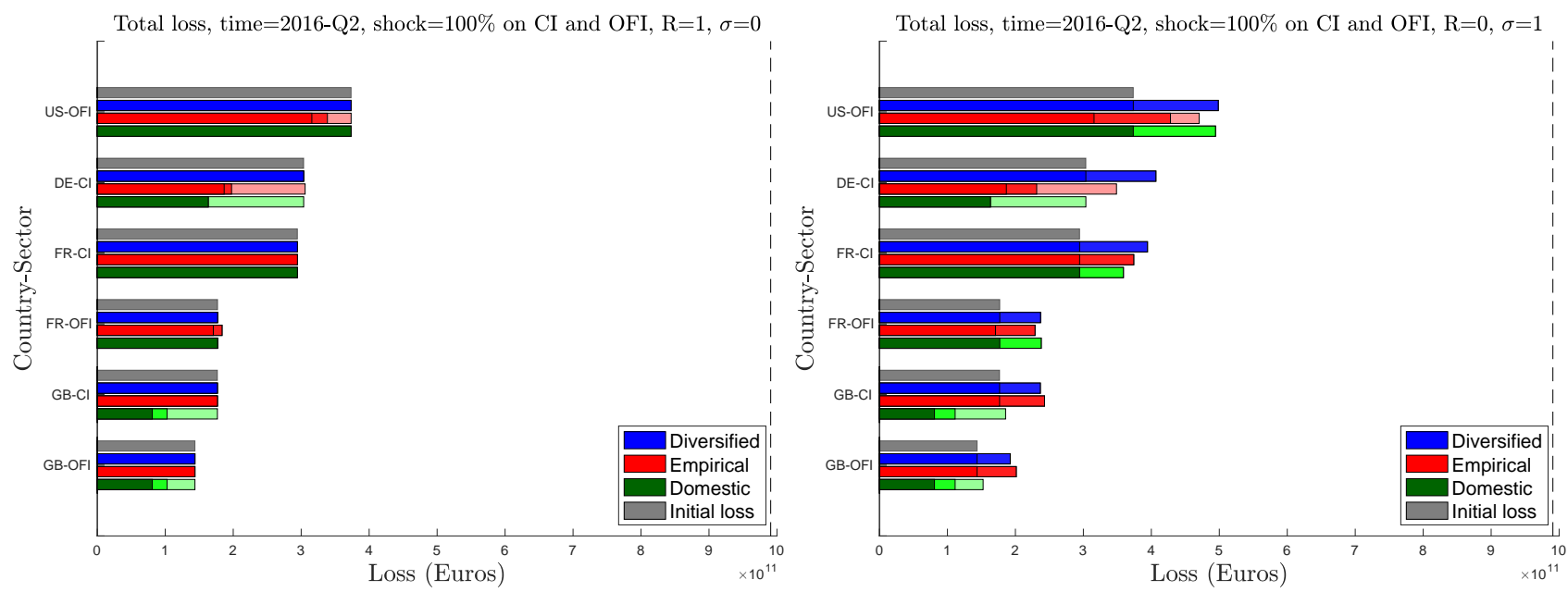

Figure 6: Impact of an exogenous shock on the financial system originating from credit institutions and other financial institutions sectors of selected countries. Each country sector is associated with four bars: (1) the gray bar represents the initial loss in value suffered by the country sector without considering network effects, (2) the blue bar represents losses suffered by the financial system under the diversified allocation of exposures assumption, (3) the red bar represents losses suffered by the financial system in the empirical setting, and (4) the green bar represents losses suffered by the financial system under the domestic allocation of exposures assumption. Additionally, each bar, except for the gray one, is split into three parts: (1) the darkest part represents the first-round losses, (2) the middle part represents the second-round losses, and (3) the lightest part represents losses suffered by creditors that are external to the financial system considered in this project. Moreover, country sectors are ranked according to their size. Additionally, the dashed vertical lines represent the total equity in the system. Left: $100 \%$ shock on the selected country sectors under the assumption of a 100\% recovery rate and $0 \%$ market volatility. Right: $100 \%$ shock on the selected country sectors under the assumption of a $0 \%$ recovery rate and $100 \%$ market volatility.

We verify the resilience of the system to a shock to potentially more risky sectors, i.e. related to losses on exposures to financial institutions. In Fig. 6, we illustrate the results of a contagion mechanism instigated by an extremely severe loss (100\% default rate) on exposures to banks and other financial institutions in one given country at a time. It is a stylized shock but can shed light on risks stemming from a default-prone sector during a time of financial market distress. Second-round losses are present for both recovery rate $0 \%$ and $100 \%$ but materially large in the former case. Interestingly, by ranking the country sectors according to the severity of the losses incurred on exposures to financial institutions, it can be observed that the exposures to US financial institutions emerge as those potentially creating the largest contagion losses in the system. This statement is true both for first-round losses and for second-round losses. This observation is important for understanding that not only the monitoring of EU cross-border exposures is necessary to understand potential vulnerabilities, but also 
significant linkages in the global network of exposures have to be detected to adequately measure the systemic risk facing the euro area banking sector.

\subsection{Leverage overlap as a measure of systemic risk}

In this section, we compare the leverage overlap and losses due to financial contagion assessed using Barucca et al. (2016a) in order to verify whether the former could be used as an indicator for systemic risk building up in financial networks.

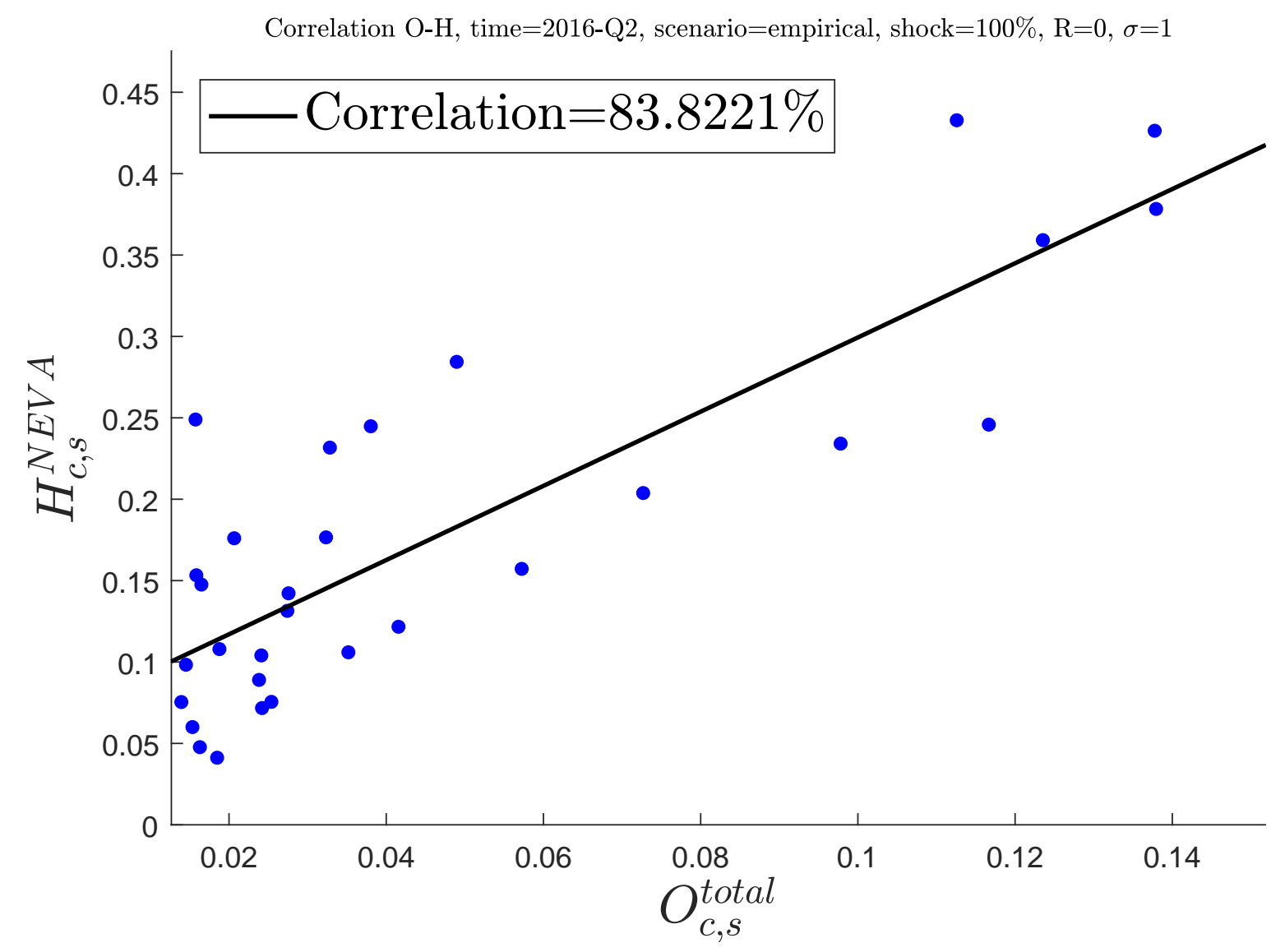

Figure 7: Correlation between leverage overlap and losses due to financial contagion. We show the correlation between leverage overlap on each country-sectors and the effects of a $100 \%$ shock on that same country-sector. Additionally, for clarity, i.e. to avoid presenting country-sectors that have very small leverage overlap or impact on the banking system, we only consider the top 30 countrysectors ranked by leverage overlap. Recovery rate is set to $R=1$ and market volatility to $\sigma=1$. Right: evolution of the correlation between leverage overlap and losses due to financial contagion according to different values of recovery rate $R$ and market volatility $\sigma$.

As shown in Fig. 7, the leverage overlap is a good indicator of financial contagion risk. The 
correlation between the two is large. In fact, by interpolating the recovery rate and market volatility parameters between zero and one, we observe an average correlation of $81.41 \%$ with a relative standard deviation of $0.52 \%$. This notwithstanding, since the average level of correlation observed is lower than one, to exactly quantify the impact of a shock on the banking system and to fully capture network effects, a more precise model for tracing contagion channels has to be applied.

Summing up, the simple mathematical measure combining the architecture of exposures to common economic sectors with the capacity of banks to absorb potential losses is a good indicator of systemic risk related to portfolio overlaps. It measures how much banks are exposed to similar risk factors and the indirect consequences of fire sales.

\subsection{Contagion under the adverse scenario of the EBA 2016 stress-test exercise}

Our framework can be applied to study contagion triggered by a consistent and market-wide shock, as in established stress-test exercises conducted by prudential authorities, such as the US Federal Reserve and the ECB/EBA EU-wide stress tests. First, from a policy application perspective, it allows for extensions of the solvency stress-test toolkits that capture first-round effects with an indirect contagion channel related to the asset commonality. Second, it serves as a benchmark to assess how severe the assumptions used in subsection 4.2 regarding the magnitude of shocks to one particular sector can be. As an illustration, we apply a shock structure to the exposures of the banks in line with the stress scenario underlying the 2016 EBA stress-test exercise.

To test the impact of a scenario that is severe and system wide but plausible, we considered credit risk shocks linked to the 2016 EBA stress-test adverse scenario. ${ }^{14}$ The scenario is constructed based on a macro-economic narrative that assumes a reversal of global risk premia, weak profitability of banks, public debt sustainability issues and distress originating from a growing shadow banking sector. ${ }^{15}$ Therefore, it reflects a market-wide disruption with the degree of severity consistent across countries and sectors. Based on the assumptions about the macro-economic conditions in line with the narrative, the EBA provided with the country-specific conditional forecasts of the main macrofinancial variables, such as GDP, inflation, unemployment, interest rates, etc. Banks subject to the stress-test exercise are asked to project risk drivers in their books conditional on the macro-economic variables, in particular probabilities of default (PD) and loss-given default (LGD) of loans.

The EBA disclosed a subset of information submitted by the banks, including the impairment rate for loans broken down by economic portfolios and countries. This piece of information is especially useful for our purposes and we extracted portfolio- and country-specific impairment rates as a proxy

\footnotetext{
${ }^{14}$ https://www.eba.europa.eu/risk-analysis-and-data/eu-wide-stress-testing/2016/results

15 https://www. eba.europa.eu/documents/10180/1383302/2016+EU-wide+stress+test-Adverse+ macro-financial+scenario.pdf
} 


\begin{tabular}{|c|c|c|c|c|c|c|c|c|c|c|c|c|c|c|c|c|c|c|c|c|c|c|c|c|c|c|c|c|c|c|c|c|c|c|c|}
\hline \multicolumn{36}{|c|}{ Household } \\
\hline & $\mathrm{AU}$ & AT & $\mathrm{BE}$ & $B R$ & CA & $\mathrm{CN}$ & $\mathrm{CR}$ & $\mathrm{CZ}$ & EG & $\mathrm{FI}$ & $F R$ & $\mathrm{DE}$ & $\mathrm{HK}$ & $\mathrm{HU}$ & IN & $\mathrm{IE}$ & IT & $J P$ & LU & $\mathrm{MH}$ & $\mathrm{MX}$ & $\mathrm{NL}$ & $\mathrm{PL}$ & RO & $\mathrm{RU}$ & SA & SG & SK & ZA & ES & SE & $\mathrm{CH}$ & $T R$ & GB & US \\
\hline AT & & 0.8 & & & & & 2.0 & 0.6 & & & & 1.1 & & 1.9 & & & & & & & & & $\begin{array}{l}1.4 \\
\end{array}$ & 1.9 & & & & 0.7 & & & & & & 0.1 & 1.3 \\
\hline $\mathrm{BE}$ & & & 0.2 & & & & & 0.7 & & 0.2 & 1.0 & 0.3 & & 1.6 & & 1.3 & 0.3 & & 0.0 & & & 0.4 & & & & & & 1.7 & & 1.5 & & & & 1.7 & 0.0 \\
\hline DK & & & & & & & & & & 0.3 & 0.2 & 0.3 & & & & 1.2 & & & & & & & & & & & & & & & 0.1 & 0.4 & & 0.3 & 0.2 \\
\hline $\mathrm{FI}$ & & & & & 0.0 & & & & & 0.1 & 0.0 & 0.0 & & & & & & & 0.1 & & & 0.0 & & & & & & & & & 0.1 & & & & \\
\hline$F R$ & & & 0.2 & & & & & 0.4 & & & 0.3 & 1.1 & & & & & 1.1 & 0.0 & 0.3 & & & 0.0 & & & 0.1 & & & & & 0.0 & & 0.0 & 4.2 & 0.1 & 0.1 \\
\hline $\mathrm{DE}$ & & 0.8 & & & & 0.5 & & & & & 0.1 & 0.3 & & & 0.6 & & 0.6 & & 0.2 & & & 0.4 & 0.5 & & & & & & & 0.7 & & 0.3 & & 0.3 & 0.3 \\
\hline IT & & 0.6 & & & & & 1.0 & 0.5 & 0.0 & & 0.1 & 0.4 & & & & & 0.7 & & 0.1 & & & & 0.3 & & 0.6 & & & 1.3 & & 0.1 & & & 0.3 & 0.4 & 0.3 \\
\hline NL & 0.1 & & 0.5 & 1.4 & 0.4 & & & & & & 0.4 & 0.4 & & & & & 0.2 & & & & & 0.3 & 1.0 & & & & 0.3 & & & 0.1 & & 0.6 & & 0.5 & 0.5 \\
\hline ES & & & & & & & & & & & 1.1 & 0.7 & & & & & 0.6 & & & & 10.8 & & & & & & & & & 0.9 & & & 20.6 & 0.4 & 0.3 \\
\hline GB & & & 0.8 & 0.0 & 0.1 & 0.4 & & & & & 0.5 & 3.4 & 0.4 & & & 1.3 & 0.4 & & & & & 0.2 & & & & 0.0 & 0.0 & & 1.5 & & & 0.9 & & 0.5 & 1.7 \\
\hline
\end{tabular}

\begin{tabular}{|c|c|c|c|c|c|c|c|c|c|c|c|c|c|c|c|c|c|c|c|c|c|c|c|c|c|c|c|c|c|c|c|c|c|c|c|}
\hline & & & & & & & & & & & & & & & & & & & & & & & & & & & & & & & & & & & \\
\hline & $A U$ & AT & $\mathrm{BE}$ & BR & CA & $\mathrm{CN}$ & CR & $\mathrm{CZ}$ & EG & $\mathrm{FI}$ & FR & $\mathrm{DE}$ & $\mathrm{HK}$ & $\mathrm{HU}$ & IN & $\mathrm{IE}$ & IT & $J P$ & LU & $\mathrm{MH}$ & $\mathrm{MX}$ & $\mathrm{NL}$ & PL & RO & $\mathrm{RU}$ & SA & SG & SK & ZA & ES & SE & $\mathrm{CH}$ & TR & GB & US \\
\hline AT & & 0.8 & & & & & 1.7 & 0.7 & & & & 1.4 & & 1.0 & & & & & & & & & 3.3 & 4.0 & 1.2 & & & 1.4 & & & & & & 0.3 & 0.2 \\
\hline $\mathrm{BE}$ & & & 0.3 & & & & & 1.0 & & & 0.2 & 0.5 & & 0.9 & & 0.8 & 1.0 & & 0.1 & & & 0.6 & & & & & & 1.0 & & 0.2 & & & & 0.7 & 0.2 \\
\hline DK & & & & & & & & & & 0.1 & 0.1 & 0.1 & & & & 0.2 & & & & & & & & & & & & & & & 0.2 & 0.0 & & 0.1 & 0.0 \\
\hline $\mathrm{FI}$ & & & & & & & & & & 0.4 & 0.0 & 0.4 & & & & & & & & & & 0.1 & & & & & & & & & 0.2 & & & & \\
\hline$F R$ & & & 0.3 & & & & & 0.5 & & & 0.4 & 0.2 & & & & & 0.6 & 0.2 & 0.4 & & & 0.2 & & & 0.1 & & & & & 0.6 & & 0.2 & 0.2 & 0.2 & 0.2 \\
\hline DE & & 0.2 & & 0.4 & 0.1 & 0.3 & & & & & 0.1 & 0.4 & & & 0.5 & 0.1 & 0.7 & & 0.4 & 1.4 & & 0.6 & 1.2 & & & & & & & 0.8 & & 0.1 & & 0.4 & 0.3 \\
\hline IT & & 0.2 & & & & & 0.8 & 0.6 & 5.1 & & 0.2 & 0.2 & & & & & 1.4 & & 0.4 & & & & 0.3 & & 0.3 & & & 1.9 & & 0.5 & & & 0.3 & 0.2 & 0.1 \\
\hline $\mathrm{NL}$ & 0.3 & & 0.7 & 0.6 & 0.2 & & & & & & 0.3 & 0.3 & & & & & 0.5 & & & 0.4 & & 0.9 & 1.6 & & & & 0.3 & & & 0.6 & & 0.2 & & 0.4 & 0.3 \\
\hline ES & & & & 0.4 & & & & & & & 0.9 & 0.4 & & & & & 1.5 & & & & 0.6 & & & & & & & & & 1.2 & & & 0.1 & 0.4 & 0.3 \\
\hline $\mathrm{GB}$ & & & 0.1 & 1.8 & 0.4 & 0.3 & & & & & 0.2 & 0.1 & 0.2 & & & 1.7 & 0.1 & 0.0 & 0.3 & & & 0.2 & & & & 0.0 & 0.2 & & 0.5 & & & 0.2 & & 0.6 & 0.2 \\
\hline
\end{tabular}

Figure 8: Table showing relative credit risk shocks, in \% (i.e. loss rates = fraction of defaulting exposures $\times$ loss-given default) suffered by banks based on domicile of banks and broken down by geographies of investments in the adverse scenario used by EBA during the 2016 stress-test exercise. Banks' domiciles determine the row of the table while the country of the asset class determines the column of the table. The top table shows the relative shock suffered in case of loans to households (household sector); the bottom table shows the relative shock suffered in the case of exposures to corporations (aggregate corporate sector).

of loan losses under the adverse macro-financial conditions. We compiled the available information for two categories of exposures - households and the non-financial corporate sector - in Tab. 8 .

The loan losses that we computed based on the EBA data on stressed impairment rates are bank specific. ${ }^{16}$ Each bank reports impairment rates for its main geographical activities. We were able to map non-financial corporate rates into multiple non-bank corporate sectors and retail secured on real estate into housing market exposures. We used country aggregates for the internal-rating-based portfolios provided by the EBA and summed up the impairment for three years of the stress-test horizon that represent the aggregate loan losses. A simple aggregation of impairment rates is justified by the static balance sheet assumed in the stress test, i.e. the gross exposures were assumed to remain constant during the stress-test horizon.

Fig. 9 shows the distribution of first- and second-round relative losses suffered by banks under the EBA adverse scenario. The impact is heterogeneous across the banks in the sample both for the first- and the second-round losses and can be quite sizable for some of the banks. For several banks the second-round effects associated with banks' interconnectedness are comparable in magnitude with

\footnotetext{
${ }^{16}$ https://www.eba.europa.eu/risk-analysis-and-data/eu-wide-stress-testing/2016/results
} 


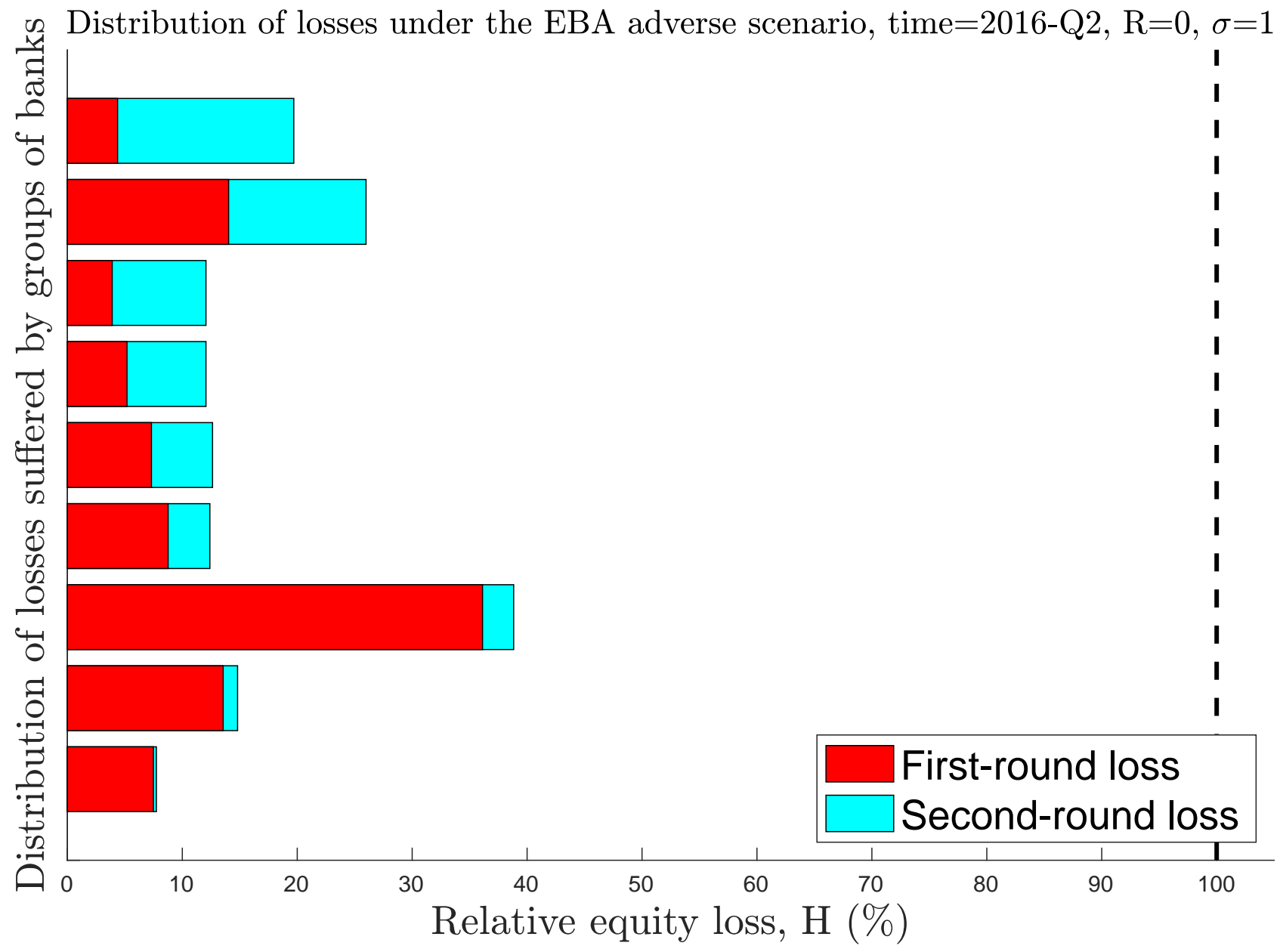

Figure 9: Distribution of relative equity losses suffered by banks in a consistent macrofinancial scenario designed for the EBA 2016 EU-wide stress-test exercise. Recovery rate $R$ is assumed to be 0 and market volatility $\sigma$ is assumed to be equal to 1 . Due to confidentiality issues, banks have been aggregated into nine groups sorted by second-round relative losses, i.e. banks that have the largest second-round losses are in the first group shown at the top and so on, until banks that have the lowest second-round relative losses, shown at the bottom of the chart.

first-round losses, and for three banks in the sample more than three times higher. The analysis based on the EBA scenario provides a benchmark against which to assess the severity of the stylized loss scenarios considered in the paper. To the results of contagion in the empirical network of exposures with losses triggered by the EBA adverse scenario in the two alternative allocation of exposures, see annex F. The outcomes of the analysis with the EBA stress-test scenario confirm that network effects should not be neglected when assessing financial stability.

There is a very important policy implication of the analysis based on the EBA stress-test scenario. 
The second-round financial contagion effects should not be disregarded by prudential authorities trying to assess risk of adverse macro-financial conditions. Our result confirms the relevance of networkbased analysis of interconnectedness to detect financial vulnerabilities, which is complementary to the standard supervisory stress tests of individual banks.

\section{Conclusion}

We conducted an analysis of contagion risk related to common exposures of banks to assets, covering a comprehensive set of asset categories. To this end, we defined a novel measure of contagion capturing a risk that a shock in a given market segment in a given country hits highly leveraged exposures. In other words, the losses implied by a unit size of a shock may erode a high portion of capital buffers. We applied the constructed measure to a granular, confidential data set of the largest European banks reporting exposures, broken down by countries and sectors of the economy according to the European industry standard classification system (NACE). Moreover, we ran several experiments to assess contagion risk that influenced pricing of financial claims, based on the NEVA approach (Barucca et al., 2016a), accounting for pertinent network effects. In the simulations we benchmarked the results based on the observed network with contagion spreading in some stylized topologies of the financial system, reflecting either a full diversification of exposures or a concentration of exposures on the domestic market.

The second-round effects of adverse market conditions and related to banks' interconnectedness are significant. We highlight this inherent feature of the financial system based on stylized simulations and confirm the importance of the network-based loss amplification channel by running our model under a plausible and consistent stress scenario used by European prudential authorities for their regular stress-test exercise.

Most importantly, we found that the diversified network of financial linkages provides a better cushion for a small-sized shock to the system than either the observed or a domestic configuration of the system. However, larger shocks imply a reversal of the relationship: the diversified system propagates the shocks much more severely than the domestic one. However, when using the relative equity loss as a measure of impact, we cannot observe that a more diversified structure is more stable for small shocks than a more domestically oriented structure. Interestingly, this second observation is at odds with the findings of Acemoglu et al. (2015), who worked in a more stylized set-up.

Conclusions based on analysis of the three architectures of banks' exposures contribute to the discussion about the European Capital Market Union. Specifically, we showed that total contagion losses may be larger in a banking system with fully diversified exposures than in the one with domestic exposures which is more concentrated. However, while a diversified financial system maximizes losses 
suffered by banks, it insulates external creditors, such as retail depositors, which suffer less losses than in a domestically concentrated system of exposures.

Future work on the project may involve an extension of the data set to cover a larger number of banks in the EU and an application of the model to calibrate sector-specific capital requirements of banks. 


\section{References}

Abad, J., D’Errico, M., Killeen, N., Luz, V., Peltonen, T., Portes, R., and Urbano, T. (2017). Mapping the interconnectedness between EU banks and shadow banking entities. Working Paper National Bureau of Economic Research No. 23280.

Acemoglu, D., Ozdaglar, A., and Tahbaz-Salehi, A. (2015). Systemic Risk and Stability in Financial Networks. American Economic Review, 105(2):564-608.

Bardoscia, M., Battiston, S., Caccioli, F., and Caldarelli, G. (2015). DebtRank: A microscopic foundation for shock propagation. PLoS ONE, 10(6):e0134888.

Bardoscia, M., Battiston, S., Caccioli, F., and Caldarelli, G. (2017). Pathways towards instability in financial networks. Nature Communications, 8(0):7.

Barucca, P., Bardoscia, M., Caccioli, F., D’Errico, M., Visentin, G., Caldarelli, G., and Battiston, S. (2016a). Network Valuation in Financial Systems. ssrn.com/abstract=2795583.

Barucca, P., Bardoscia, M., Caccioli, F., D'Errico, M., Visentin, G., Caldarelli, G., and Battiston, S. (2016b). Network Valuation in Financial Systems. Working Paper ssrn 2795583, pages 1-16.

Battiston, S., Caldarelli, G., D'errico, M., and Gurciullo, S. (2016). Leveraging the network : a stress-test framework based on DebtRank. Statistics and Risk Modeling, 33(3-4):1-33.

Battiston, S., Puliga, M., Kaushik, R., Tasca, P., and Caldarelli, G. (2012). DebtRank: Too Central to Fail? Financial Networks, the FED and Systemic Risk. Scientific Reports, 2:1-6.

Caccioli, F., Shrestha, M., Moore, C., and Farmer, J. D. (2014). Stability analysis of financial contagion due to overlapping portfolios. Journal of Banking \& Finance, 26(4):835-866.

Cifuentes, R., Ferrucci, G., and Shin, H. S. (2005). Liquidity risk and contagion. Journal of the European Economic Association, 3(2-3):556-566.

Clerc, L., Giovannini, A., Langfield, S., Peltonen, T., Portes, R., and Scheicher, M. (2016). Indirect contagion: the policy problem. ESRB Occasional Paper Series 09, European Systemic Risk Board.

Cont, R., Moussa, A., Santos, E. B., and Others (2013). Network structure and systemic risk in banking systems. Handbook of Systemic Risk, pages 327-368.

Cont, R. and Schaanning, E. (2018). Monitoring indirect contagion. Technical report. 
Cont, R. and Wagalath, L. (2014). Fire sales forensic: measuring endogenous risk. Mathematical Finance, 46(C):233-245.

Duarte, F. M. and Eisenbach, T. M. (2013). Fire-sale spillovers and systemic risk. Staff reports, Federal Reserve Bank of New York.

Düllmann, K. and Masschelein, N. (2007). A tractable model to measure sector concentration risk in credit portfolios. Journal of Financial Services Research, 32(1):55-79.

ECB (2016). Topical issue: Macroprudential effects of systemic bank stress. Macroprudential Bulletin, 2.

Eisenberg, L. and Noe, T. H. (2001). Systemic Risk in Financial Systems. Management Science, $47(2): 236-249$.

Gai, P., Haldane, A., and Kapadia, S. (2011). Complexity, concentration and contagion. Journal of Monetary Economics, 58(5):453-470.

Hałaj, G. (2013). Systemic Valuation of Banks: Interbank Equilibrium and Contagion, pages 57-83. Springer Berlin Heidelberg, Berlin, Heidelberg.

Hałaj, G. (2018). System-wide implications of funding risk. Physica A: Statistical Mechanics and its Applications, 503:1151 - 1181 .

Hałaj, G., Kochanska, U., and Kok, C. (2015). Emergence of EU corporate lending network. Journal of Network Theory in Finance, 1(1):1-44.

Hałaj, G. and Kok, C. (2013). Assessing interbank contagion using simulated networks. Computational Management Science, 10(2-3):157-186.

Rogers, L. C. G. and Veraart, L. A. M. (2013). Failure and rescue in an interbank network. Management Science, 59(4):882-898.

Silva, T. C., da Silva Alexandre, M., and Tabak, B. M. (2018). Bank lending and systemic risk: A financial-real sector network approach with feedback. Journal of Financial Stability, 38:98 - 118.

Stiglitz, J. E. (2018). Where modern macroeconomics went wrong. Oxford Review of Economic Policy, $34(1-2): 70-106$.

Visentin, G., D'Errico, M., and Battiston, S. (2016). Rethinking Financial Contagion. Working Paper ssrn 2831143. 
Wagner, W. (2011). Systemic liquidation risk and the diversity-diversification trade-off. The Journal of Finance, 66(4):1141-1175. 


\section{A The data set}

In collaboration with the European Central Bank, we analyze a large data set that includes the exposures of 26 large European banks. Each exposure is labeled with the country and sector of the obligor, as well as the relative instrument and time snapshot. Additionally, we estimate bilateral exposures among those 26 banks. We save those exposures into four-dimensional matrices. Each dimension of the generalized matrix corresponds to one characteristic of banks' exposures. For instance, the letter $i$ represents the banks' index. Here we summarize the properties of the generalized matrices and illustrate the size of the data set. We ignore the instrument dimensions because exposures are observed empirically to be composed mostly of loans. For this reason, we decided to aggregate exposures along the instrument dimension.

- $i \in\{1,2, \ldots, 26\}$ is bank index,

- $c \in\{1,2, \ldots, 272\}$ is country index,

- $s \in\{1,2, \ldots, 22\}$ is sector index of items on the following list:
A - Agriculture, forestry and fishing,
B - Mining and quarrying,
C - Manufacturing,
CI - Credit institutions,
D - Electricity, gas, steam and air conditioning supply,
E - Water supply,
F - Construction,
G - Wholesale and retail trade,
H - Transport and storage,
HH - Households,
I - Accommodation and food service activities,
J - Information and communication,
L - Real estate activities,
M - Professional, scientific and technical activities,
$\mathbf{N}$ - Administrative and support service activities,
O - Public administration and defense, compulsory social security, 
OFI - Other financial institutions,

$\mathbf{P}$ - Education

Q - Human health services and social work activities,

$\mathbf{R}$ - Arts, entertainment and recreation,

$\mathbf{S}$ - Other services

- $t \in\{1,2, \ldots, 7\}$ is time index.

\section{B Generating synthetic allocations of exposures}

In this annex we provide a short description of the methodology for generating the diversified and domestic allocations of exposures for non-banks. ${ }^{17}$

\section{B.1 Diversified allocation}

The re-shuffled generalized matrix of assets is simply defined as follows:

$$
A_{i, c, s, t}^{\text {diversified }}=\frac{\sum_{i} A_{i, c, s, t}}{\sum_{i, c, s} A_{i, c, s, t}} \cdot \sum_{c, s} A_{i, c, s, t},
$$

which corresponds to the product between the relative size of the selected country sector (in respect of the global economy) and the total assets of bank $i$.

\section{B.2 Domestic allocation}

For each country $c, B_{c}$ indicates the subset of banks (from the original 26) in it. $\sum_{i, s} A_{i, c, s, t}$ is the size of the economy of the selected country. $\sum_{i \in B_{c}} A_{i, c, s, t}$ is the sum of the balance sheets of the banks in that country. Let $q$ be the ratio between the total balance sheet in that country and the size of its economy, $q_{c}=\frac{\sum_{i \in B_{c}} \sum_{c, s} A_{i, c, s, t}}{\sum_{i, s} A_{i, c, s, t}}$.

- if $q_{c} \leq 1$, it means that the size of the banks is not sufficient to fill their domestic economy. In this case

$$
\forall i \in B_{c}, \quad A_{i, c, s, t}^{\text {domestic }}=\frac{\sum_{i} A_{i, c, s, t}}{\sum_{i, c, s} A_{i, c, s, t}} \cdot \sum_{c, s} A_{i, c, s, t} .
$$

- if $q_{c}>1$, the country is not big enough to host the balance sheets of its banks. For this reason only a part of their assets is allocated; the rest is kept suspended and distributed in a second

\footnotetext{
${ }^{17}$ A reconstruction of the interbank networks follows Hałaj and Kok $(2013)$, as in subsection 3.3
} 
step of the algorithm. More precisely,

$$
\forall i \in B_{c}, \quad A_{i, c, s, t}^{\text {domestic }}=\frac{1}{q_{c}} \cdot \frac{\sum_{i} A_{i, c, s, t}}{\sum_{i, c, s} A_{i, c, s, t}} \cdot \sum_{c, s} A_{i, c, s, t} .
$$

The remaining exposures are then allocated as for the diversified scenario, respecting the constraints given by balance sheet and country-sector size, $(28)$ and $(29) .{ }^{18}$

\section{B.3 Balance-sheet constraints}

For any fictitious allocation of the exposures, the following three constraints are respected: the total assets of each bank in equation (28) and the size of each country sector in equation (29) are equal to the observed figures, and capital buffers are preserved. Formally,

$$
\begin{aligned}
& \sum_{c, s} A_{i, c, s, t}=\sum_{c, s} A_{i, c, s, t}^{\mathrm{div}}=\sum_{c, s} A_{i, c, s, t}^{\mathrm{dom}}, \quad \forall i, t \\
& \sum_{i} A_{i, c, s, t}=\sum_{i} A_{i, c, s, t}^{\mathrm{div}}=\sum_{i} A_{i, c, s, t}^{\mathrm{dom}}, \quad \forall c, s, t .
\end{aligned}
$$

\section{The NEVA framework}

We build on Barucca et al. (2016a) in order to compute the value of interbank claims in a network setting. In fact, we observe empirically that banks are both exposed (via loans) to each other and they are exposed to a set of external asset classes. For this reason the values of interbank claims are interdependent. Further, we assume that a portion of banks' assets will be affected by an exogenous shock and that, from the time of the valuation of claims to their maturity, the value of surviving external assets is subject to market volatility. While the market volatility could have any functional form, in our project we consider a uniform distribution.

In the model, we want to reflect banks' risk management practice when they decide which risky asset class to invest into. To this end, we define market volatility as a random variable with uniform distribution between 0 and $M$, where $M$ is determined by the exogenous parameter $\sigma$

$$
M_{i}=\max \left\{0, \min \left\{A_{i}^{e}, \sigma E_{0 i}\right\}\right\} .
$$

Equation (30) means that due to market volatility, bank $i$ can lose not more than a value proportional to its initial equity. Additionally, because of limited liability the loss is constrained to the amount of

\footnotetext{
${ }^{18}$ The approach is consistent with that used to generate the domestic interbank market.
} 
external assets that bank $i$ holds.

Note that $\sigma$ is not a standard deviation per se. We use the boundaries of the distribution as an equivalent measure of dispersion to simplify estimation of the relationship between risk and contagion losses and for a better understanding of the shock size relative to the capital base necessary to instigate contagion.

As shown in Barucca et al. (2016a), the valuation function is defined as

$$
\mathbb{V}_{i, j}=1-p_{j}^{D}\left(E_{j}\right)+R \rho_{j}\left(E_{j}\right)
$$

where $p_{j}^{D}$ is bank's $j$ probability of default, $R$ is the exogenous recovery rate, and $\rho_{j}$ is bank's $j$ endogenous recovery rate.

Additionally, because the dynamics depend on the reciprocal of the support of market volatility, we define the default probability and the exogenous recovery rate if $M_{j}=0$.

$\underline{M_{j}=0:}$

- In the absence of market volatility, either because bank $j$ has no external assets or because its value does not change from the valuation to maturity, the probability of default simply reads

$$
\begin{aligned}
p_{j}^{D}\left(E_{j}\right) & =\mathbb{E}\left[\mathbb{1}_{E_{j}(T)<0}\right]= \\
& =\mathbb{1}_{E_{j}<0} .
\end{aligned}
$$

In other words, bank $j$ defaults before maturity if and only if its equity is lower than zero.

- Similarly, the endogenous recovery rate is

$$
\begin{aligned}
\rho_{j}\left(E_{j}\right) & =\mathbb{E}\left[\left(\frac{E_{j}(T)+\bar{p}_{j}}{\bar{p}_{j}}\right)^{+} \mathbb{1}_{E_{j}(T)<0}\right]= \\
& =\left(\frac{E_{j}+\bar{p}_{j}}{\bar{p}_{j}}\right) \mathbb{1}_{E_{j}<0} \mathbb{1}_{E_{j}+\bar{p}_{j} \geq 0},
\end{aligned}
$$

where $\bar{p}_{j}=\sum_{j} L_{j i}$ corresponds to the total interbank liabilities of bank $j$.

$M_{j}>0:$

- In the presence of market volatility, the probability of bank's $j$ default before maturity might be non-zero, even though its equity is positive when the valuation is carried out (consistent with the classic Merton model of valuation of contingent claims). More precisely, if the support of the market volatility $M_{j}$ is larger than $j$ 's equity, then the probability that bank $j$ will default 
before maturity is positive.

$$
\begin{aligned}
p_{j}^{D}\left(E_{j}\right) & =\mathbb{E}\left[\mathbb{1}_{E_{j}(T)<0}\right]= \\
& =\int_{0}^{M_{j}} d x \frac{1}{M_{j}} \mathbb{1}_{x>E_{j}}= \\
& =\frac{1}{M_{j}}[x]_{\max \left\{0, E_{j}\right\}}^{M_{i}} \mathbb{1}_{M_{j}>E_{j}}= \\
& =\left(1-\frac{\max \left\{0, E_{j}\right\}}{M_{j}}\right) \mathbb{1}_{M_{j}>E_{j}} .
\end{aligned}
$$

- Similarly, if the equity of bank $j$ is smaller than the size of the support of market volatility of its external assets, the probability that the bank will not be able to honor its interbank obligations is non-zero.

$$
\begin{aligned}
\rho_{j}\left(E_{j}\right) & =\mathbb{E}\left[\left(\frac{E_{j}(T)+\bar{p} j}{\bar{p}_{j}}\right)^{+} \mathbb{1}_{E_{j}(T)<0}\right]= \\
& =\int_{0}^{M_{j}} d x \frac{1}{M_{j}}\left(\frac{E_{j}-x+\bar{p}_{j}}{\bar{p}_{j}}\right) \mathbb{1}_{x>E_{j}} \mathbb{1}_{E_{j}-x+\bar{p}_{j}>0}= \\
& =\int_{A}^{B} d x \frac{1}{M_{j}}\left(\frac{E_{j}-x+\bar{p}_{j}}{\bar{p}_{j}}\right) \mathbb{1}_{A<B},
\end{aligned}
$$

where $A=\max \left\{0, E_{j}\right\}$ and $B=\min \left\{M, E_{j}+\bar{p}_{j}\right\}$. We can thus write

$$
\begin{aligned}
\rho_{j}\left(E_{j}\right) & =\int_{A}^{B} d x \frac{1}{M_{j}}\left(\frac{E_{j}-x+\bar{p}_{j}}{\bar{p}_{j}}\right) \mathbb{1}_{A<B}= \\
& =\int_{A}^{B} d x \frac{1}{M_{j}}\left(\frac{E_{j}+\bar{p}_{j}}{\bar{p}_{j}}\right) \mathbb{1}_{A<B}+\int_{A}^{B} d x \frac{1}{M_{j}}\left(\frac{-x}{\bar{p}_{j}}\right) \mathbb{1}_{A<B}= \\
& =\left[\frac{(B-A)\left(E_{j}+\bar{p}_{j}\right)}{M_{j} \bar{p}_{j}}+\frac{A^{2}-B^{2}}{2 M_{j} \bar{p}_{j}}\right] \mathbb{1}_{A<B} .
\end{aligned}
$$

Further, it can be shown that equation (34) converges to equation (32) and that equation (36) converges to equation (33) when $\sigma$ decreases. In particular, when setting the market volatility to zero and recovery rate to one, the Eisenberg and Noe (2001) model is recovered. In more detail, in the absence of market volatility, the distance to maturity is irrelevant since the value of external assets does not change in time. Thus, an ex-ante valuation coincides with a valuation carried out at the maturity of contracts. Furthermore, when the recovery rate is set to zero, losses induced by financial frictions, such as legal costs, are not considered. In fact, it turns out that both the assumption on a valuation of financial assets carried out at maturity and the assumption of absence of financial frictions 
are in common with the Eisenberg and Noe (2001) model. It is also worth noting that when market volatility is set to one and the recovery rate to zero the model of (Bardoscia et al. 2015$)$ is recovered. In fact, when $\sigma$ is equal to one, market losses can be equal to a bank's capital base. ${ }^{19}$ In this setting, it can be shown that the probability of default of a bank coincides to the relative equity loss that the same bank suffered.

\section{Proofs of propositions}

In this section we are going to provide the proofs to the propositions stated in the paper.

Proposition 1. NEVA encompasses the Eisenberg and Noe model.

When $R=1$ and $\sigma=0$, there is a one-to-one correspondence between the solutions of equation (10) and the solutions of the map $\Phi$ introduced in Eisenberg and Noe (2001).

Proof. The correspondence follows derivations shown in C.

Proposition 2. NEVA encompasses the DebtRank model.

When $R=0$ and $\sigma=1$, there is a one-to-one correspondence between the solutions of equation (10) and the solutions of the recursive map (linear DebtRank) introduced in Bardoscia et al. (2015).

Proof. The correspondence follows derivations shown in C

Proposition 3. Losses are non-decreasing with the size of the initial shock $k$.

If the valuation function $\mathbb{V}$ is feasible, under the same financial network structure, recovery rate $R$ and market volatility $\sigma$, losses suffered by each bank after financial contagion cannot be smaller if the initial shock $k$ is larger, i.e.

$$
\Xi_{i}\left(k_{1}, R, \sigma\right) \geq \Xi_{i}\left(k_{2}, R, \sigma\right), \text { if } k_{1} \geq k_{2}
$$

Proof. From the definition of feasible valuation function, it follows that $\mathbb{V}\left(s_{1}\right) \geq \mathbb{V}\left(s_{1}\right)$, if $s_{1} \leq s_{1}$ because the equity of banks is non-increasing with the size of the shock. Since the equity of banks is a non-decreasing function of $\mathbb{V}$, the proposition is proved.

Proposition 4. Losses are non-increasing with the recovery rate $R$.

If the valuation function $\mathbb{V}$ is feasible, under the same financial network structure, initial shock $k$ and market volatility $\sigma$, losses suffered by each bank after financial contagion cannot be smaller if the

\footnotetext{
${ }^{19}$ The measure might seem non-standard compared with a usual definition of market volatility based on standard deviation of prices. But the one we consider is equivalent, yet easier to interpret as far as losses on market risk exposures relative to banks' capital are concerned.
} 
recovery rate $R$ is smaller, i.e.

$$
\Xi_{i}\left(k, R_{1}, \sigma\right) \geq \Xi_{i}\left(k, R_{2}, \sigma\right), \text { if } R_{1} \leq R_{2} .
$$

Proof. The valuation function we use in this paper $\mathbb{V}$ is a non-decreasing function with the recovery rate $R$. Since the equity of banks is a non-decreasing function of $\mathbb{V}$, the proposition is proved.

Proposition 5. Losses are non-decreasing with the market volatility $\sigma$.

If the valuation function $\mathbb{V}$ is feasible, under the same financial network structure, initial shock $k$ and recovery rate $R$, losses suffered by each bank after financial contagion cannot be smaller if the market volatility $\sigma$ is larger, i.e.

$$
\Xi_{i}\left(k, R, \sigma_{1}\right) \geq \Xi_{i}\left(k, R, \sigma_{2}\right), \text { if } \sigma_{1} \geq \sigma_{2}
$$

Proof. The valuation function we use in this paper $\mathbb{V}$ is a non-increasing function with the market volatility $\sigma$. Since the equity of banks is a non-decreasing function of $\mathbb{V}$, the proposition is proved.

Proposition 6. There is a relationship between leverage overlap and losses due to financial contagion.

In the context of limited liabilities, when losses are estimated using Barucca et al. (2016a), the following inequality holds:

$$
H_{c, s}^{\text {total }} \geq k \cdot O_{c, s}^{\text {total }}
$$

where $H_{c, s}^{\text {total }}$ is the total relative equity loss suffered by banks and external creditors weighted on banks' equity, $k$ is the relative shock affecting the country sector, and $O_{c, s}^{\text {total }}$ is the total leverage overlap computed according to equation (6).

Proof. As shown in Visentin et al. (2016), absent an amplification, total losses are simply proportional to the total leverage and the relative shock.

$$
\left.H_{c, s}^{\text {total }}\right|_{\text {no amplification }}=k \cdot \Lambda_{c, s}^{\text {total }} .
$$

Moreover, because of amplification of losses due to network effects, total losses can never be lower than this bound but might be larger. The last equation can thus be rewritten as

$$
H_{c, s}^{\text {total }} \geq k \cdot \Lambda_{c, s}^{\text {total }}
$$


It is now simple to use equation (9) to prove proposition 1.

$$
H_{c, s}^{\mathrm{total}} \geq k \cdot \Lambda_{c, s}^{\text {total }} \geq k \cdot O_{c, s}^{\text {total }}
$$

Proposition 7. There is a relationship between first-round losses in domestic and diversified settings.

In a context with limited liabilities, when the exogenous shock only hits a single asset class, firstround losses in the domestic setting $\Xi_{1 \mathrm{st}}^{\mathrm{dom}}$ are never larger than first-round losses in the diversified setting $\Xi_{1 \mathrm{st}}^{\mathrm{div}}$; more precisely,

$$
\Xi_{1 \mathrm{st}}^{\mathrm{div}} \geq \Xi_{1 \mathrm{st}}^{\mathrm{dom}}
$$

Proof. First-round losses are computed summing losses suffered by a bank that is exposed to the exogenous shock. Therefore, first-round losses are at most equal to the loss in value of the shocked asset classes. Because of limited liabilities, if the initial shock exceeds the equity of shocked banks, only a part of losses is accounted in first round. In detail, for any network topology,

$$
\Xi_{1 \mathrm{st}}=\sum_{i} \min \left\{E_{i},\left(\sum_{c} \sum_{s} A_{i, c, s} \cdot k_{c, s}\right)\right\} .
$$

The min operator selects the first term (i.e. banks' equity) if and only if losses are larger than equity. Because of how it is constructed, in the empirical setting individual exposures are larger than equity only in a highly concentrated topology. It follows that in the diversified allocation of exposures, limited liabilities has an impact only if the size of the sector is larger than the total equity of banks in the database. $^{20}$ On the contrary, the domestic allocation of exposures is much more concentrated than the diversified one. For this reason, limited liabilities is applied for a larger set of country-sectors and the inequality stated in the proposition becomes strict. This completes the proof.

Proposition 8. There is a relationship between losses suffered by external creditors in domestic and diversified settings

In the context of limited liabilities, losses suffered by external creditors in the diversified setting $\Xi_{\text {ext }}^{\text {div }}$ are never larger than losses suffered by external creditors in the domestic setting $\Xi_{\text {ext }}^{\text {dom }}$. More precisely,

$$
\Xi_{\text {ext }}^{\operatorname{div}} \leq \Xi_{\text {ext }}^{\text {dom }}
$$

\footnotetext{
${ }^{20}$ In our dataset this is true only for one country sector.
} 

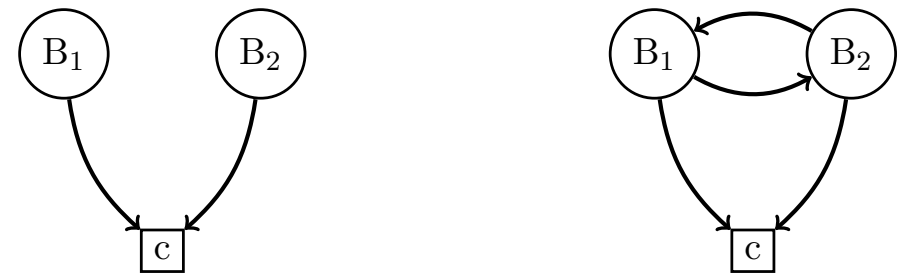

Figure 10: Comparison of leverage overlap and losses due to financial contagion in two simple networks. Left: two banks are exposed to the same asset class c. Right: two banks are exposed to the same asset class c and they are exposed to each other on the interbank market as well.

Proof. The proof is similar to the previous one. When amplification of distress is limited, total losses in the domestic and diversified allocations of exposures are similar. On the one hand, due to the higher density of financial contracts in the diversified allocation of exposures, the capital of all banks is used to absorb the initial loss. On the other hand, due to the modularity of the financial system, only a small number of banks is affected by the initial shock in the domestic allocation of exposures. By expressing the losses suffered by external creditors as the difference between the total losses and the losses absorbed by banks' capital, we prove proposition 3 .

\section{E Stylized example of how the overlap measure works}

To illustrate where the leverage overlap indicator fails to capture systemic risk, let us consider the following networks: (i) two banks exposed to the same asset class, and (ii) two banks exposed to the same asset class and to each other across bilateral contracts. Fig. 10 shows the two networks: the network without interbank exposures is shown on the left-hand side of the figure, and the network with interbank exposures is shown on the right.

Let us assume that the two banks are identical and their balance sheets are composed as follows:

- $A_{i}^{e}=8 €$ are the total external assets of each bank,

- $A_{i, c}^{e}=2 €$ is the part of external assets invested in asset class c,

- $L_{i}^{e}=2 €$ are the total external liabilities of each bank.

Additionally, for the network on the right-hand side of Fig. 10, interbank exposure is as follows:

- $A_{i, j}^{b}=3 €$ is the amount that bank $i$ invested in bank $j$,

- $L_{i, j}^{b}=3 €$ is the amount that bank $i$ owes to bank $j$. 
First, we compute the initial equity $E_{0}$ of each bank as the difference of total assets (interbank and external) and total liabilities (interbank and external). For both networks, the initial equity of each bank $E_{0}$ is 6 . Because of symmetry, the computation of the leverage overlap generalized matrix is straightforward. Following equation (2), we have

$$
O_{i, j}=\min \left\{\frac{A_{i}^{e}}{E_{0, i}}, \frac{A_{j}^{e}}{E_{0, j}}\right\}=\frac{A_{i}^{e}}{E_{0, i}}=\frac{A_{j}^{e}}{E_{0, j}}=\frac{2 €}{6 €}=\frac{1}{3} .
$$

From equation (6), the total overlap follows:

$$
O^{\text {total }}=\frac{\sum_{j} \sum_{i \neq j}\left(E_{0, i} \cdot O_{i, j}\right)}{(N-1) \sum_{i} E_{0, i}}=\frac{6 € \cdot \frac{1}{3}+6 € \cdot \frac{1}{3}}{(2-1)(6 €+6 €)}=\frac{1}{3} .
$$

To compare the two networks, we now compute total losses due to a $100 \%$ relative shock on asset class c. Here we neglect the banks' index because the formula is symmetric.

\section{- Network without interbank}

The relative equity loss $h$ suffered by each bank directly follows the definition in Battiston et al. (2016):

$$
\begin{aligned}
h & =\min \left\{1, \frac{E_{0}-E_{1}}{E_{0}}\right\}=\min \left\{1, \frac{E_{0}-\left(\left(A^{e}-k\right)-L^{e}\right)}{E_{0}}\right\}= \\
& =\min \left\{1, \frac{6 €-((8 €-2 €)-2 €)}{6 €}\right\}=\min \left\{1, \frac{2 €}{6 €}\right\}=\frac{1}{3}
\end{aligned}
$$

which means that each bank lost one-third of its equity due to direct exposure to the external shock. Additionally, the total relative equity loss is

$$
H^{\text {total }}=\frac{E_{0} h+E_{0} h}{E_{0}+E_{0}}=\frac{6 € \cdot \frac{1}{3}+6 € \cdot \frac{1}{3}}{6 €+6 €}=\frac{1}{3} .
$$

We notice that

$$
H^{\text {total }}=O^{\text {total }}
$$

which in this case holds because the network of leverage is symmetric and interbank exposures are absent.

\section{- Network with interbank}

In order to compute losses due to financial contagion according to the NEVA framework, we start from a result derived from the network without interbank exposures: after assessing losses 
due to the exogenous shock, the equity of each bank is

$$
E_{1}=A^{e}-L^{e}+A^{b}-L^{b}=(8 €-2 €)-2 €+3 €-3 €=4 €
$$

where the index 1 to the equity indicates the first step of the NEVA algorithm.

To apply the NEVA framework we start by computing the total interbank liability $\bar{p}$ and the support of the market volatility of external assets $M$ considering $\sigma=1$,

$$
\begin{aligned}
\bar{p} & =\sum_{j} L_{i, j}^{b}=3 €, \\
M & =\min \left\{A^{e}-A_{c}^{e}, \sigma E_{0}\right\}=\min \{8 €-2 €, 1 \cdot 6 €\}=6 € .
\end{aligned}
$$

Assuming that the interbank recovery rate $R$ is zero, we now compute the losses due to financial contagion.

$$
\begin{aligned}
E_{2} & =A^{e}-A_{c}^{e}-L^{e}+\mathbb{V} A^{b}-L^{b}= \\
& =A^{e}-A_{c}^{e}-L^{e}+\left[1-\left(1-\frac{\max \left\{0, E_{1}\right\}}{M}\right)_{\left.\mathbb{1}_{M<E_{1}}\right]} A^{b}-L^{b}=\right. \\
& =8 €-2 €-2 €+\left[1-\left(1-\frac{\max \{0,4 €\}}{6 €}\right)_{\mathbb{1}_{6 €>4}}\right] 3 €-3 €=3 € .
\end{aligned}
$$

After one iteration of the NEVA framework, banks $B_{1}$ and $B_{2}$ have lost $50 \%$ of their equity. It then follows:

$$
\frac{1}{2}=H^{\text {total }}>O^{\text {total }}=\frac{1}{3},
$$

which still satisfies proposition 1 but, because of network effects, is not an equality anymore. In particular, if we iterate the methodology until the fixed point is reached, we obtain

$$
E_{\infty}=2
$$

which means that banks have lost two-thirds of their initial equity. More precisely,

$$
\frac{2}{3}=H^{\text {total }}=2 \cdot O^{\text {total }}=2 \cdot \frac{1}{3}
$$

which confirms previous empirical results stating that, under certain assumptions, losses due to financial contagion might be of similar size to losses due to direct exposures Visentin et al. (2016). 


\section{F EBA adverse scenario in diversified and domestic topologies}

As a benchmark, we compute losses due to financial contagion triggered by the EBA adverse scenario in the two alternative allocations of exposures. Notice that loss aggregation is allocation specific (i.e. the way banks are grouped in order to maintain anonymity is different in the two alternative allocations of exposures).
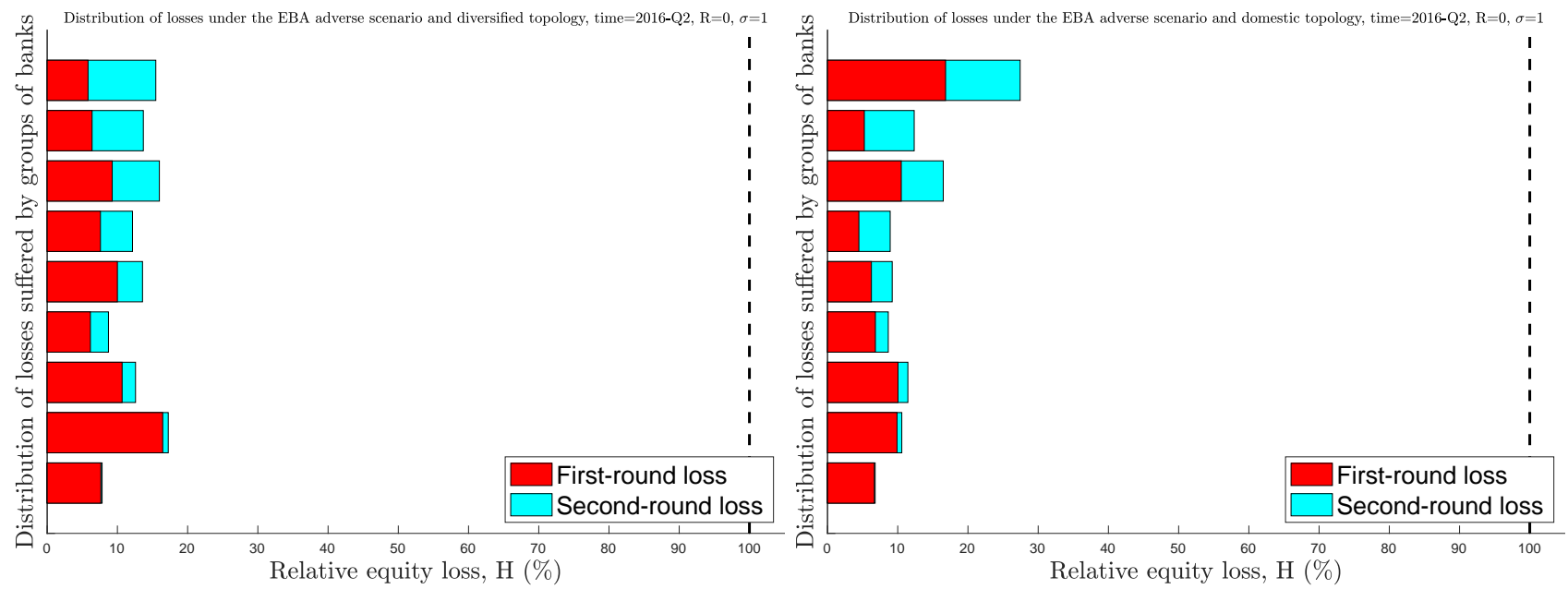

Figure 11: Distribution of relative equity losses suffered by banks in a consistent macrofinancial scenario designed for the EBA 2016 EU-wide stress-test exercise. Left: distribution of losses in the diversified allocation of exposures. Right: distribution of losses in the domestic allocation of exposures. Recovery rate $R$ is assumed to be 0 and market volatility $\sigma$ is assumed to be equal to 1 . Due to confidentiality issues, banks have been aggregated into nine groups, sorted by second-round relative losses, i.e. banks that have the largest second-round losses are in the first group shown at the top and so on, until banks that have the lowest second-round relative losses, shown at the bottom of the chart.

In Fig. 11, we observe that losses in the domestic allocation of exposures are more concentrated than losses in the diversified allocation of exposures. While the EBA adverse scenario consists of a set of correlated shocks that affect many banks at the same time, in the domestic allocation of exposures, second-round losses are confined within countries. For this reason, second-round losses are large when banks of the same country have a large total interbank leverage. On the contrary, second-round losses are smaller in the diversified allocation of exposure because interbank leverage is distributed among all other banks. 